\title{
All-trans retinoic acid results in irregular repair of septa and fails to inhibit proinflammatory macrophages
}

\author{
C. Seifart*, J.P. Muyal",,ף,\#\#, A. Plagens*,\#\#, A.Ö. Yildirim, ${ }^{\#,+}$ K. Kohse ${ }^{+}$, V. Grau ${ }^{\S}$, \\ S. Sandu ${ }^{\#}$, C. Reinke*, T. Tschernig ${ }^{f}$, C. Vogelmeier* and H. Fehrenbach ${ }^{\#, * *}$
}

ABSTRACT: All-trans retinoic acid (ATRA) is controversially discussed in emphysema therapy. We re-evaluated ATRA in the elastase model and hypothesised that beneficial effects should be reflected by increased alveolar surface area, elastin expression and downregulation of inflammatory mediators and matrix metalloproteinases (MMPs).

Emphysema was induced by porcine pancreatic elastase versus saline in Sprague-Dawley rats. On days 26-37, rats received daily intraperitoneal injections with ATRA (500 $\mu \mathrm{g} \cdot \mathrm{kg}^{-1} \mathrm{body}$ weight) versus olive oil. Lungs were removed at day 38. Rat alveolar epithelial L2 cells were incubated with/without elastase followed by ATRA- or vehicle-treatment, respectively.

ATRA only partially ameliorated structural defects. Alveolar walls exhibited irregular architecture: increased arithmetic mean thickness, reduction in surface coverage by alveolar epithelial cells type II. ATRA only partially restored reduced soluble elastin. It tended to increase the ratio of $\mathrm{ED1}^{+}: \mathrm{ED2}^{+}$macrophages. Bronchoalveolar lavage (BAL) cells exhibited a proinflammatory state and high expression of interleukin-1ß, cytokine-induced neutrophil chemoattractant-1, tumour necrosis factor- $\alpha$, nuclear factor-кB, MMP-2, MMP-9, MMP-12, tissue inhibitor of metalloproteinase (TIMP)-1 and TIMP-2 in emphysema, with ATRA exerting only few effects. MMP-7 was highly induced by ATRA in healthy but not in emphysematous lungs. ATRA reduced both MMP-2 and TIMP-1 activity in BAL fluid of emphysematous lungs.

ATRA-therapy may bear the risk of unwanted side-effects on alveolar septal architecture in emphysematous lungs.

KEYWORDS: All-trans retinol, emphysema, macrophages, matrix metalloproteinases, pulmonary alveoli, regeneration

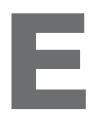
mphysema is a chronic pulmonary disease with increasing incidence and a high socioeconomic burden. Destruction of the distal lung with resulting loss of gas exchanging alveoli is the defining morphological characteristic of pulmonary emphysema [1]. Therapeutic options are limited and at best stabilise the current status of the disease. At present, there are no therapeutic options available that allow for the regeneration of lost alveoli in emphysematous human lungs.

All-trans retinoic acid (ATRA) was demonstrated to rescue the lungs of mice and rats from dexamethasone-induced inhibition of postnatal formation of alveolar septa [2-5]. In addition, several experimental studies in rats and mice suggested that regeneration of lost alveolar septa can be achieved by ATRA in elastase- or cigarette smoke-induced emphysema [6-8]. However, a number of studies failed to demonstrate a beneficial effect of ATRA in other emphysema models [9-14], and beneficial effects in human patients have been marginal so far [15-18]. The reason for these discrepancies is still unclear [19]. Although potential mechanisms underlying the beneficial effects of ATRA in dexamethasoneinduced impairment of alveolarisation have been suggested [20-23], only little is known about the molecular mechanisms contributing to its potential regenerative effects in smoke- or elastaseinduced emphysema [16, 19].

Formation of alveolar septa during postnatal lung development, repair and regeneration is characterised by complex interactions of various types of cells and extracellular matrix components involving specific transcription factors, cytokines and proteases. Remodelling of the extracellular matrix is a key feature of postnatal alveolar septation [24] with various matrix metalloproteinases (MMPs),
AFFILIATIONS

*Dept of Internal Medicine, Division of Respiratory Medicine, University Hospital Giessen and Marburg $\mathrm{GmbH}$,

${ }^{\#}$ Clinical Research Group Chronic Airway Diseases, Faculty of Medicine, Philipps University, Marburg,

${ }^{+}$Comprehensive Pneumology Center, Institute of Lung Biology and Disease, Helmholtz Zentrum München, Neuherberg, Munich, ${ }^{\S}$ Laboratory of Experimental Surgery, Dept of General and Thoracic Surgery, Justus-Liebig-University Giessen, Giessen,

${ }^{f}$ Functional and Applied Anatomy, Hanover Medical School, Hanover, and

**Section of Experimental

Pneumology, Research Center Borstel, Leibniz Centre for Medicine and Biosciences, Borstel, Germany. -School of Biotechnology, Gautam Buddha University, Greater Noida, Uttar Pradesh, India.

\#\#Both authors contributed equally.

CORRESPONDENCE

C. Seifart

Dept of Internal Medicine

Division of Respiratory Medicine

University Hospital Giessen and

Marburg GmbH

35043 Marburg

Germany

E-mail: seifart@med.uni-marburg.de

Received:

Aug 032009

Accepted after revision:

Jan 052011

First published online:

Jan 272011

European Respiratory Journal Print ISSN 0903-1936 Online ISSN 1399-3003 
zinc-dependent endopeptidases, involved [25, 26]. Gelatinase A (MMP-2), gelatinase B (MMP-9) and macrophage metalloelastase (MMP-12) play a key role in emphysema development and progression [27-29]. However, MMPs are not only involved in the development of pulmonary diseases, but also appear to be important in repair and defence mechanisms. MMP-7 is involved in the control of inflammation [30], and is required for airway re-epithelialisation [31]. Both MMP-7 and MMP-9 directly modulate the activity of several growth factors, which are involved in tissue repair and remodelling [31]. Under normal physiological conditions MMPs promote remodelling of extracellular matrix, while in pathological conditions a switch in MMP expression and activity may lead to excessive lung inflammation and tissue destruction.

Because the potential of ATRA to induce alveolar regeneration in elastase-induced emphysema in rodents is controversially discussed, we tested ATRA in the same rat strain using the same experimental design as in the original study of MASSARO and MASSARO [7]. Quantitative stereology was used to assess alveolar tissue destruction by elastase and the potential regenerative effect of ATRA. To investigate the regenerative potential on a molecular level, we analysed the extracellular matrix protein elastin, a key component of alveolar septa [32]. Because MMP-2, MMP-7, MMP-9 and MMP-12, and their inhibitors tissue inhibitor of metalloproteinase (TIMP)-1 and TIMP-2 are involved in matrix remodelling and pulmonary repair, we hypothesised that the regenerative effect of ATRA, if present, should affect MMP and TIMP levels. To address this question, we studied expression and enzyme activity of MMP-2, MMP-7, MMP-9, MMP-12, TIMP-1 and TIMP-2 in alveolar macrophages and whole lung tissue homogenate by means of RT-PCR, western blotting, immunohistochemistry, zymography, and/or reverse zymography in control and elastase-induced emphysematous rat lungs treated with ATRA or vehicle, respectively. Furthermore, as ATRA is thought to dampen inflammatory processes, proinflammatory mediators tumour necrosis factor (TNF)- $\alpha$, interleukin (IL)- 1 , cytokine-induced neutrophil chemoattractant (CINC)-1 and nuclear factor (NF)- $\kappa \mathrm{B}$ were investigated too. To assess the potential contribution of pulmonary epithelial cells, the effects of elastase and ATRA were studied in the rat alveolar epithelial cell (AEC) type II cell line L2.

\section{MATERIAL AND METHODS Experimental design}

All in vivo animal experiments were performed according to institutional guidelines that complied with national and international regulations, and have been approved by the regional government (Regierungspräsidium Giessen, Dezernat V 54, Giessen, Germany). 6-week-old male Sprague-Dawley rats with a body weight (bw) of $\sim 150 \mathrm{~g}$ were randomly assigned to four different groups (fig. 1).

1) Control group (sham/sham (SS)): at day 0 , rat lungs $(n=6)$ received a single bolus of $180 \mu \mathrm{L}$ saline (sham) by endotracheal instillation. From day 26 to day 37, animals received an intraperitoneal injection of $300 \mu \mathrm{L} \cdot \mathrm{kg}^{-1}$ bw olive oil (sham) each day. 2) ATRA control group (sham/ATRA (SA)): at day 0 , saline was instilled into rat lungs $(n=6)$ by endotracheal instillation. From day 26 to day 37, animals received an intraperitoneal injection of $500 \mu \mathrm{g} \cdot \mathrm{kg}^{-1} \mathrm{bw}$ ATRA dissolved in olive oil (300 $\mu \mathrm{L} \cdot \mathrm{kg}^{1}$ bw) each day. 3) Emphysema-treatment group (elastase/ATRA (EA)): at day 0, lung emphysema was induced in rats $(n=6)$ by endotracheal instillation of $25 \mathrm{U} \cdot \mathrm{kg}^{-1}$ bw porcine pancreatic elastase (Roche Diagnostics, Mannheim, Germany). From day 26 to day 37, animals received an intraperitoneal injection of $500 \mu \mathrm{g} \cdot \mathrm{kg}^{-1} \mathrm{bw}$ ATRA (Sigma-Aldrich, Steinheim, Germany) dissolved in olive oil $\left(300 \mu \mathrm{L} \cdot \mathrm{kg}^{-1} \mathrm{bw}\right)$ each day. 4) Emphysema group (elastase/sham (ES)): at day 0, lung emphysema was induced in rats $(n=6)$ as described for group 3. From day 26 to day 37, animals received a sham intraperitoneal injection of olive oil $\left(300 \mu \mathrm{L} \cdot \mathrm{kg}^{-1} \mathrm{bw}\right)$ per day.

All animals were sacrificed at day 38. Lungs were perfused with sterile PBS to remove blood. Bronchoalveolar lavage (BAL) was performed prior to separation of the right lung for quantitative morphology and the left lung for investigation of relative mRNA expression.

\section{$B A L$ and isolation of alveolar macrophages}

BAL fluid was collected from both lungs by injecting each with $6 \mathrm{~mL}$ of PBS per injection to recover a final volume of $42 \mathrm{~mL}$. Alveolar macrophages were recovered from BAL fluid by centrifugation at $168 \times \mathrm{g}$ for $15 \mathrm{~min}$, re-suspended in RLT buffer (Qiagen, Hilden, Germany) and stored at $-80^{\circ} \mathrm{C}$ until analysed.

\section{Lung fixation}

Right lungs were fixed by airway instillation with $4 \%$ phosphate-buffered paraformaldehyde at a pressure of $20 \mathrm{~cm}$ water column. After overnight fixation in fresh fixative, right lung volume was determined by fluid displacement and two fractions of lung slices were collected by systematic uniform random sampling, as described elsewhere [29], for subsequent embedment into paraffin and glycol methacrylate (GMA), respectively. In order to assess potential effects of ATRA on the inflammatory cell infiltrate, four lungs of each therapeutic group, i.e. ES and EA, were fixed without prior BAL.

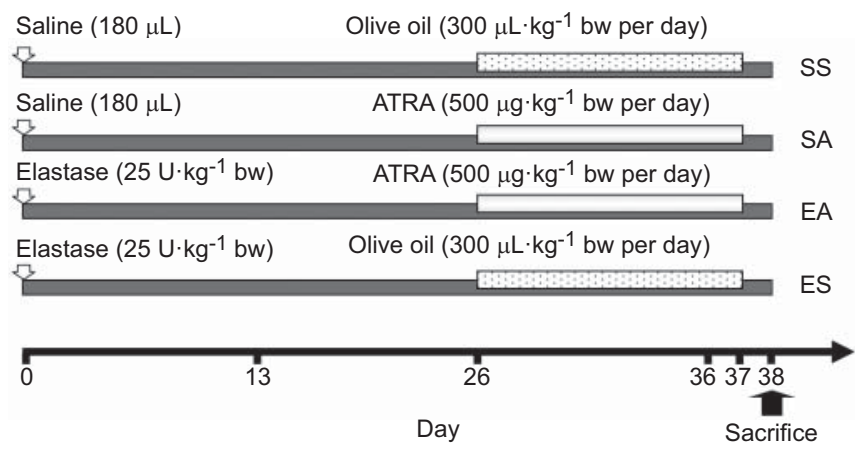

FIGURE 1. Experimental setup. On day 0 , rats received a single bolus of $180 \mu \mathrm{L}$ of saline with or without $25 \mathrm{U} \cdot \mathrm{kg}^{-1}$ body weight (bw) of porcine pancreatic elastase. From day 26 to day 37, animals received an intraperitoneal injection of $300 \mu \mathrm{L} \cdot \mathrm{kg}^{-1}$ bw of olive oil alone (sham) or with $500 \mu \mathrm{g} \cdot \mathrm{kg}^{-1} \mathrm{bw}$ of all-trans retinoic acid (ATRA) each day. At day 38, animals were sacrificed and lungs removed for analysis by quantitative morphology and molecular biology. SS: saline/sham group; SA: saline/ATRA; EA: elastase/ATRA group; ES: elastase/sham group. 


\section{Tissue processing}

One fraction of right lung slices was post-fixed in $1 \%$ glutardialdehyde, $1 \%$ paraformaldehyde in $0.1 \mathrm{M}$ sodium cacodylate buffer followed by osmication, and en bloc staining with aqueous uranyl acetate prior to dehydration. These lung slices were embedded into GMA for stereological analysis of lung parenchyma as described recently [33]. The second fraction of lung slices was directly processed for routine embedment into paraffin for subsequent immunohistochemistry.

\section{Immunohistochemistry}

Immunohistochemical staining for markers of inflammatory cells was performed as described recently [34]. In detail, monoclonal antibodies (mAbs) ED1, ED2 and R73 were purchased from Serotec (Düsseldorf, Germany). Horseradish peroxidise-conjugated rabbit anti-mouse immunoglobulins and the anti-mouse EnVision peroxidase system were supplied by DAKO (Hamburg, Germany). Polyclonal rabbit antisera against myeloperoxidase and MMP-7 were purchased from LifeSpan Biosciences (Biozol, Eching, Germany) and Acris Antibodies (Herford, Germany), respectively. The polyclonal antiserum against surfactant protein A was kindly provided by $\mathrm{S}$. Hawgood (University of California, San Francisco, CA, USA).

Slides were treated with $0.5 \mathrm{mg} \cdot \mathrm{mL}^{-1}$ Protease Type XIV (Sigma-Aldrich, Taufkirchen, Germany) in $50 \mathrm{mM}$ Tris- $\mathrm{HCl}$ buffer, $\mathrm{pH} 7.6$, containing $0.9 \% \mathrm{NaCl}$ for $15 \mathrm{~min}$ at room temperature. Endogenous peroxidase activity was blocked with $1 \% \mathrm{H}_{2} \mathrm{O}_{2}$ in PBS for $30 \mathrm{~min}$. After washing in PBS, the sections were incubated for $30 \mathrm{~min}$ with PBS, pH 7.2, 1\% bovine serum albumin (Serva, Heidelberg, Germany), 0.1\% $\mathrm{NaN}_{3}$ (Merck, Darmstadt, Germany) followed by overnight incubation with an appropriate dilution of primary antibody (ED1 1:500, ED2 1:200, R73 1:500) in the same solution at $4{ }^{\circ} \mathrm{C}$. On control sections, the primary antibody was omitted. Bound primary antibodies were detected using the anti-mouse EnVision peroxidase system containing $5 \%$ heat inactivated normal rat serum and 3,3'diaminobenzidine (Sigma-Aldrich, Schnelldorf, Germany). Staining for myeloperoxidase, MMP-7, and surfactant protein $\mathrm{D}$ was performed by indirect immunohistochemistry using a biotinylated goat ant-rabbit secondary antibody (Vector Laboratories, Burlinghame, CA, USA) as described earlier [35]. Sections were lightly counter-stained with hemalum.

\section{Quantitative morphology (stereology)}

From each lung slice embedded into GMA one technically excellent Richardson-stained section was used to quantify structural changes in the lung parenchyma. The following emphysema-relevant parameters were recorded as described recently [33]: mean airspace chord length and arithmetic mean septal thickness, total airspace volume, total alveolar surface area and total volume of alveolar septal wall tissue, which were normalised to body mass. In addition, paraffin sections stained for surfactant protein A by indirect immunohistochemistry were used for stereological quantification of the total alveolar surface area occupied by AEC type II, as described previously [35]. Sections stained with mAbs ED1 and ED2 were used to quantify the total volume of alveolar and interstitial macrophage subpopulations, respectively, as described previously [33]. All stereological analyses were performed using a PC-based Olympus BX 51 light microscope equipped with a Cast-Grid 2.1.5 system (Olympus, Ballerup, Denmark) following the American Thoracic Society/European Respiratory Society research policy statement [36].

\section{Processing of whole lung tissue}

Left lungs were placed on a sterile petri dish on ice and immediately chopped up with a sterile scalpel into small pieces. Chopped tissue pieces were collected in 2-mL Eppendorf tubes, dipped into liquid nitrogen for $5 \mathrm{~min}$ and stored at $-80^{\circ} \mathrm{C}$ until analysed.

\section{Total protein extraction and western blotting for detection of elastin}

Total protein was extracted from $100 \mathrm{mg}$ whole lung tissue (WLT) homogenate using total protein extraction kit (Biochain Institute, Hayward, CA, USA) according to the manufacturer's protocol. The protein amount of each sample from WLT was determined using a $\mathrm{BCA}^{\mathrm{TM}}$ protein assay kit (Pierce, Rockford, IL, USA) according to the manufacturer's recommendation. Equal amounts of protein $(100 \mu \mathrm{g})$ were mixed with Tris-glycine SDS sample buffer and reduced with $\beta$-mercaptoethanol (Sigma-Aldrich, Steinheim, Germany) at $95^{\circ} \mathrm{C}$ for $5 \mathrm{~min}$. Reduced samples along with Novex ${ }^{\circledR}$ sharp pre-stained protein standard (Invitrogen, Karlsruhe, Germany) were immediately loaded on $4-15 \%$ Tris-HCL Criterion ${ }^{\mathrm{TM}}$ pre-cast gel (Bio-Rad, Hercules, CA, USA) and were electrophoresed at $60 \mathrm{~V}$ for $30 \mathrm{~min}$ and $120 \mathrm{~V}$ for $90 \mathrm{~min}$. The separated proteins were transferred to Protran ${ }^{\mathrm{TM}}$ nitrocellulose membranes (Protran, Dassel, Germany), which were blocked with 5\% skimmed milk in PBS (Biochrom, Berlin, Germany) for $1 \mathrm{~h}$. Blocked membranes were incubated overnight with pre-diluted anti-elastin antibody (1:200; Biozol) followed by washing three times with PBS for $5 \mathrm{~min}$ and were incubated with horseradish peroxidiselinked secondary antibody (1:1000; Pierce) for $1 \mathrm{~h}$. The membranes were washed three times with PBS for $5 \mathrm{~min}$. The washed membranes were exposed to enhanced chemiluminescence detection (SuperSignal ${ }_{\AA}$ West Femto; Pierce) and recorded by autoradiography (CL-X Posure ${ }^{\mathrm{TM}}$ film; Pierce).

Membranes were scanned and the obtained bands were quantified using computer-based densitometer and analysis software (Bio-1D V.97 software; Vilber Lourmat, France), which was carried out on negative images of the Western blots. Differences in optical density of protein bands were calculated with respect to controls $(100 \%)$. Since two blots were performed and each blot had three samples from each group, results were expressed as mean $\pm \mathrm{SD}$.

\section{Stimulation of epithelial cells in vitro}

Rat AEC type II (cell line L2) were seeded in 12-well plates with $1 \times 10^{5}$ cells per well and cultured in Dulbecco's modified Eagle medium (DMEM) supplemented with $10 \%$ fetal bovine serum (FBS) and 1\% penicillin/streptomycin. After $24 \mathrm{~h}, \mathrm{~L} 2$ cells were washed with PBS and serum-free DMEM was added for $12 \mathrm{~h}$ in order to cause starvation of the cells. Serumfree DMEM was removed and replaced by DMEM containing $10 \%$ FBS. Accessorily $30 \mu \mathrm{g} \cdot \mathrm{mL}^{-1}$ elastase (Sigma-Aldrich, Steinham, Germany) was added to the cells. After $6 \mathrm{~h}$ the cells were treated with $1 \mathrm{mM}$ ATRA. L2 cell supernatants for multiplex analysis were collected either $3 \mathrm{~h}$ or $5 \mathrm{~h}$ later. 
Furthermore, cells were harvested at the same time points for RT-PCR analysis.

\section{Isolation of total cellular RNA and CDNA synthesis}

To investigate the relative mRNA expression in alveolar macrophages and WLT, total cellular RNA was extracted using RNeasy columns (Qiagen) according to the manufacturer's instructions, as described previously [37]. Total RNA quantification and purity was determined with an Ultraspec 2100spectrophotometer (Amersham Pharmacia Biotech, Cambridge, UK). The quantity of the isolated RNA was calculated from the absorbance at $260 \mathrm{~nm}$, and the purity was determined by calculating the ratio at optical density $260 \mathrm{~nm} /$ optical density $280 \mathrm{~nm}$. Total RNA integrity was assessed by analysing $18 \mathrm{~S}$ and $28 \mathrm{~S}$ ribosomal RNA on $1.2 \%$ ethidium-bromide stained agarose gel electrophoresis.

First-strand cDNA was synthesised by introducing equal amounts of RNA $(1.5 \mu \mathrm{g})$ from each sample in a total reaction volume of $20 \mu \mathrm{L}$ using an oligo (dT) $)_{12-18}$ primer (Invitrogen) and Superscript ${ }^{\mathrm{TM}}$ II Reverse Transcriptase kit (Invitrogen).

\section{Relative mRNA quantification}

The real-time RT-PCR for determining the amplification factor of the target genes (table 1) were performed in a 96-well format iCycler Detection System (BioRad) in $20 \mu \mathrm{L}$ total reaction volume using $10 \mu \mathrm{L}$ of SYBR Green PCR mix (ABgene ${ }^{\circledR}$ Thermo Fisher Scientific, Epsom, UK), $1 \mu \mathrm{L}$ of each sequencespecific forward and reverse oligonucleotide primer (10 pmol), $7 \mu \mathrm{L}$ of water and $1 \mu \mathrm{L}$ of cDNA. The thermal cycle conditions used for all reactions were as follows: step $1,95^{\circ} \mathrm{C}$ for $15 \mathrm{~min}$; step 2 (40 cycles), $95^{\circ} \mathrm{C}$ for $50 \mathrm{~s}$; step 3, sequence-specific oligonucleotide primer's annealing temperature (table 1) for $40 \mathrm{~s}$; step $4,72^{\circ} \mathrm{C}$ for $40 \mathrm{~s}$; and step $5,72^{\circ} \mathrm{C}$, for $5 \mathrm{~min}$.

\section{Real-time RT-PCR data analysis}

mRNA levels for target genes MMP-2, MMP-7, MMP-9, MMP12, TIMP-1, TIMP-2, IL-1, CINC-1, TNF- $\alpha$ and NF- $\mathrm{B}$, respectively were determined relative to the endogenous control glyceraldehyde-3-phosphate dehydrogenase according to the formula, 2 to the power of delta cycle threshold $\left(2^{\Delta \mathrm{Ct}}\right)$, where $\Delta \mathrm{Ct}$ is $\mathrm{Ct}_{\text {reference gene- }} \mathrm{Ct}_{\text {test gene. }}$

\section{Multiplex analysis}

For analysis of cytokine protein levels released by L2 cells, a multiplexed bead immunoassay was performed. Samples were tested according to the manufacturer's instructions utilising a Milliplex MAP Kit on the BioPlex 100 analyser (Bio-Rad). The kit includes five different populations of microspheres coated with specific capture antibodies, in this case for: CINC-1, TNF- $\alpha$, IL-6, IL-1 $\beta$ and CXC chemokine ligand 10.

\section{Zymography and reverse zymography}

Gelatine zymography and reverse zymography were carried out on $200 \mu \mathrm{L}$ of cell free lavage fluids, which were 10-fold concentrated using Centricon YM-10 columns (Millipore, Bedford, MA, USA) with a molecular cut-off at $10 \mathrm{kD}$.

For zymography, samples were mixed with Tris-glycine SDS sample buffer (Invitrogen) and immediately loaded on Novex $10 \%$ gelatin zymogram gels (Invitrogen). Samples were electrophoresed at $120 \mathrm{~V}$ for $90 \mathrm{~min}$. Gels were renatured with zymogram renaturation buffer (Invitrogen), developed with zymogram developing buffer (Invitrogen), stained with Simply Blue $^{\mathrm{TM}}$ Safestain (Invitrogen) and destained with double distilled water according to the manufacturer's instructions.

For reverse zymography, resolving gel and stacking gel were prepared as follows. For the resolving gel, $3.3 \mathrm{~mL}$ of $30 \%$ acrylamide; $2.5 \mathrm{~mL}$ of $1.5 \mathrm{M}$ Tris $-\mathrm{HCl}, \mathrm{pH} 8.3 ; 20 \mathrm{mg} \cdot \mathrm{mL}^{-1}$ gelatin (Sigma-Aldrich, Steinheim, Germany); $35 \mathrm{ng} \cdot \mathrm{mL}^{-1}$ proMMP-2 (Calbiochem, Darmstadt, Germany); $2.85 \mathrm{~mL}$ water; $100 \mu \mathrm{L}$ of $10 \%$ SDS; $100 \mu \mathrm{L}$ ammonium persulphate (APS); and $10 \mu \mathrm{L}$ TEMED. For the stacking gel, $1.3 \mathrm{~mL}$ of $30 \%$ acrylamide; $2.5 \mathrm{~mL}$ of $0.5 \mathrm{M}$ Tris- $\mathrm{HCl}, \mathrm{pH} 6.8 ; 6.1 \mathrm{~mL}$ water; $100 \mu \mathrm{L}$ of $10 \%$ SDS; $100 \mu \mathrm{L}$ APS; and $10 \mu \mathrm{L}$ TEMED. Concentrated BAL samples were mixed with Tris-glycine SDS sample buffer and immediately loaded onto the gels. Samples were electrophoresed at $120 \mathrm{~V}$ for $90 \mathrm{~min}$. Gels were renatured, denatured and developed as described previously.

\section{Zymography and reverse zymography data analysis}

The bands obtained were quantified by a densitometer and analysis software (Bio-1D V.97 software), which was carried out on negative images of the zymograms and reverse zymograms. Differences in optical density of bands were calculated with respect to the control (100\%).

\section{Statistical analysis}

Unless otherwise stated, mean \pm SD values are given. The unpaired t-test was used to determine the level of significance of differences between SS versus SA, and ES versus EA, respectively. If normality and equal variance were not given at $\mathrm{p}>0.1$, Mann-Whitney rank sum test was used. All analyses were performed by means of GraphPad Prism 4 software program (El Camino Real, San Diego, CA, USA). Differences were considered statistically significant at $\mathrm{p}<0.05$ (SigmaStat3.1; Jandel Scientific, Erkrath, Germany).

\section{RESULTS}

\section{Quantitative morphology}

Most of the effects seen in distal lung structures resulted from elastase-treatment whereas ATRA had no effects in healthy lungs (groups SA versus SS) and ATRA-therapy was only partially effective in emphysematous lungs (groups EA versus ES) (table 2). Rats receiving a single endotracheal instillation of elastase followed by daily injections of vehicle for 12 days (group ES) exhibited all the signs of pulmonary emphysema, i.e. heterogeneous airspace enlargement and loss of alveolar septa, whereas ATRA-therapy resulted in a partial amelioration of the effects of elastase (fig. 2). Airspace enlargement was reflected by an increase in mass-specific volume of distal airspaces $(+69 \%)$ and mean chord length $(+25 \%)$ in group ES compared with group SS, i.e. saline instilled, vehicle injected animals (table 2). Loss of alveolar septa was indicated by a decrease in mass-specific alveolar septal surface area $(-24 \%)$. The arithmetic mean thickness of alveolar septal walls, however, was significantly increased $(+39 \%)$ in group ES compared with group SS.

Rats with elastase-induced emphysema, which received daily injections of ATRA for 12 days (group EA), were characterised by amelioration of airspace enlargement, indicated by a significant reduction in the mean chord length $(-12 \%)$ in 
TABLE 1 Primer sequence, annealing temperature and amplicon size of target sequence

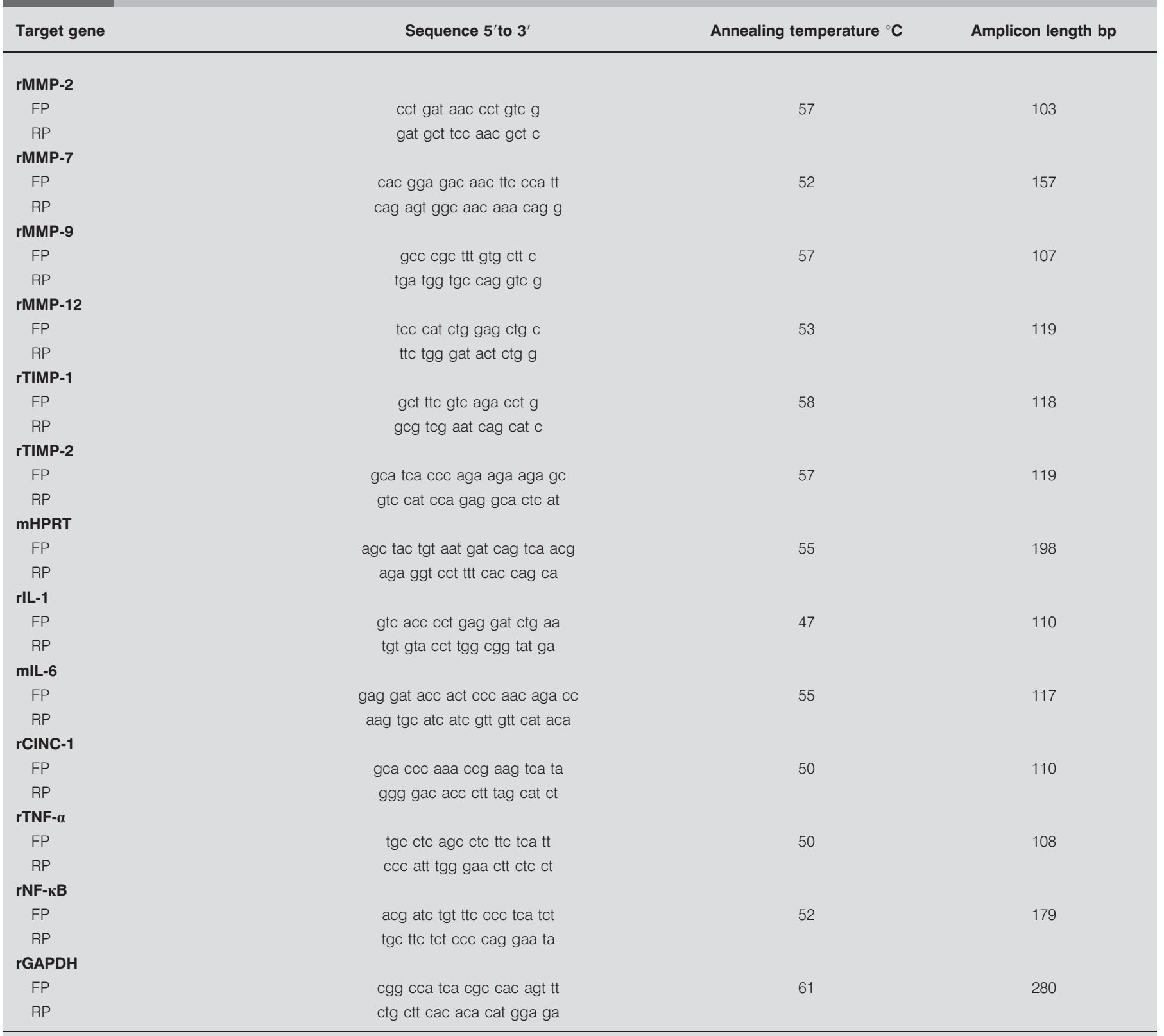

r: Rattus norvegicus; MMP: matrix metalloproteinases; TIMP: tissue inhibitor of metalloproteinase; m: Mus musculus; HPRT: hypoxanthine-guanine phosphoribosyltransferase; IL: interleukin; CINC: cytokine-induced neutrophil chemoattractant; TNF: tumour necrosis factor; NF: nuclear factor; GAPDH: glyceraldehyde-3-phosphate dehydrogenase; RP: reverse primer; FP: forward primer.

comparison with group ES (table 2). Although, the loss of alveolar septal walls was slightly less pronounced in group EA, as indicated by a reduction in mass-specific alveolar septal surface area $(-15 \%)$ compared with saline/ATRA-treated animals, it was not significantly different from group ES. Mean chord length and mass-specific volume of distal airspaces were still significantly higher in group EA than in group SA. Notably, the arithmetic mean thickness of alveolar septa was further increased in group EA compared with group ES (fig. 2d), as was also indicated by a significant increase in the mass-specific volume of alveolar septal tissue (table 2).
Notably, a significant reduction in the alveolar surface area occupied by AEC type II $(-38 \%)$ was observed in group EA versus group SA.

\section{Elastin expression}

In WLT, elastin mRNA analysed by RT-PCR was not significantly different between the groups under study (fig. 3a), whereas soluble elastin protein assessed by western blotting was significantly reduced in emphysematous rat lungs (groups ES and EA) compared with controls (group SS and SA). Although, ATRA-supplementation in emphysematous lungs did not restore 


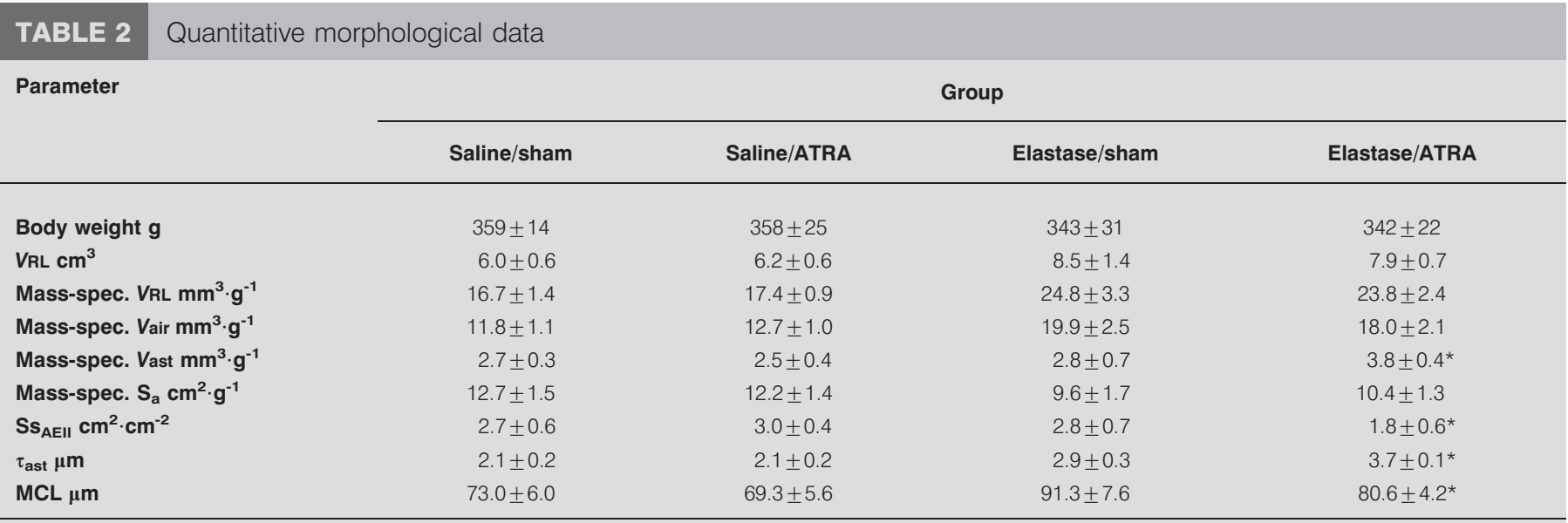

Data are presented as mean \pm SD. ATRA: all-trans retinoic acid; VRL: volume of fixed right lung; mass-spec.: mass-specific; Vair: volume of distal airspaces; Vast: volume of alveolar septal tissues; $\mathrm{S}_{\mathrm{a}}$ : surface area of alveolar septa; $\mathrm{SS}_{\mathrm{AEII}}$ : fraction of alveolar surface area occupied by alveolar epithelial type II cells; $\tau_{\text {ast }}$ : arithmetic mean thickness of alveolar septa; MCL: mean chord length of acinar airspace (alveoli and alveolar ducts). If normality and equal variance were given at $p>0.1$, the unpaired t-test was used to test for significant differences between saline/sham (SS) versus saline/ATRA and elastase/sham (ES) versus elastase/ATRA, respectively; otherwise non-parametric Mann-Whitney U-test was performed. *: $p<0.05$ versus group ES.

control levels, soluble elastin protein was significantly higher in group EA compared with ES (figs $3 b$ and c).

\section{Inflammatory cells}

Immunohistochemical staining for major inflammatory cell types, i.e. alveolar macrophages $\left(\mathrm{ED}^{+}\right)$(figs $4 \mathrm{a}$ and $\mathrm{d}$ ) and interstitial macrophages (ED2 ${ }^{+}$) (figs $4 \mathrm{~b}$ and e), T-lymphocytes $\left(\alpha / \beta\right.$-T-cell receptor ${ }^{+}$) (figs $4 \mathrm{c}$ and $\mathrm{f}$ ) and neutrophilic granulocytes (data not shown) demonstrated that $\mathrm{ED}^{+}$alveolar macrophages were the predominant cell type irrespective of the therapeutic treatment. The other cell types were only rarely
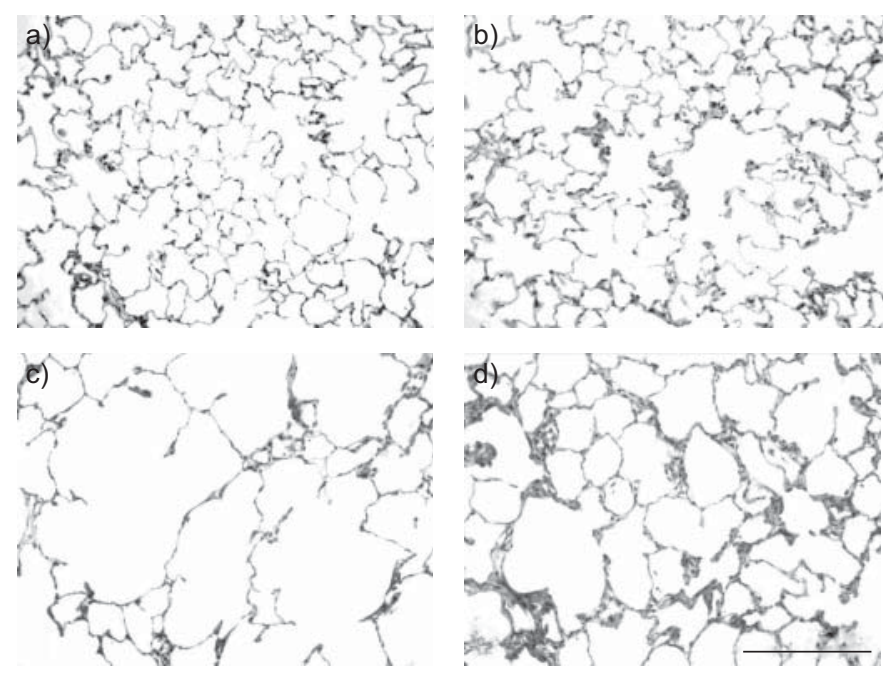

FIGURE 2. Histopathology of gas exchange area. Richardson-stained glycol methacrylate sections show: a) normal histology in saline/sham-treated animals; b) slightly thickened alveolar septa in saline/ all-trans retinoic acid (ATRA)-treated rats; c) rarefaction of alveolar septa with enlarged airspaces in elastase/sham-treated rats; and d) slightly increased airspaces with focally considerably thickened alveolar septa in elastase/ATRA-treated animals. All micrographs were taken at identical magnification. Scale bar: $300 \mu \mathrm{m}$. seen. $\mathrm{ED}^{+}$alveolar macrophages appeared to be increased in response to ATRA, whereas no changes were seen in ED2 ${ }^{+}$ macrophages. As a consequence, the ratio of $\mathrm{ED}^{+}$to $\mathrm{ED} 2^{+}$ macrophages tended to be increased $(p=0.07)$ in the EA compared with the ES group (figs $4 \mathrm{e}$ and $\mathrm{f}$ ).

\section{Inflammatory mediators}

Significant effects of elastase were observed in alveolar macrophages for all inflammatory mediators and transcription factors under study (TNF- $\alpha$, IL-1, CINC-1, NF-кB). RT-PCR revealed an increase in the mRNA levels of IL-1, CINC-1, TNF- $\alpha$ and NF- $\kappa B$ in alveolar macrophages of emphysematous (group ES) compared with control rats (group SS). None of the inflammatory mediators under study were significantly altered by ATRA-therapy in emphysematous lungs, either in alveolar macrophages (figs 5a-d) or in WLT (figs 5e and f). However, mRNA levels were affected by ATRA in healthy lungs only (SA versus SS groups): CINC-1 was increased in alveolar macrophages, whereas NF- $\kappa \mathrm{B}$ and TNF- $\alpha$ were decreased in WLT (figs 5e and f). Likewise, only minor effects were observed in rat AEC type II-like cells L2 treated with elastase and exposed to ATRA or control therapy, respectively (fig. 6). ATRA decreased IL- 6 mRNA and protein expression in EA versus ES group (figs $6 \mathrm{c}$ and $\mathrm{d}$ ), although significance was achieved for mRNA expression only.

\section{MMPs and TIMPs}

Elastase-treatment resulted in an increase in the mRNA levels of MMP-7, MMP-9 and MMP-12, as well as TIMP-1 and TIMP-2 in alveolar macrophages of emphysematous rat lungs (group ES) compared with control group SS (fig. 7).

ATRA significantly increased mRNA expression levels of MMP-2 (fig. 7a), MMP-7 (fig. 7b), MMP-9 (fig. 7c) and TIMP-2 (fig. 7f) in alveolar macrophages and MMP-7, MMP12, and TIMP-2 in WLT (data not shown) of healthy lungs (SS versus SA). ATRA-therapy resulted in a significant reduction of MMP-12 (fig. 7d), TIMP-1 (fig. 7e) and TIMP-2 expression 

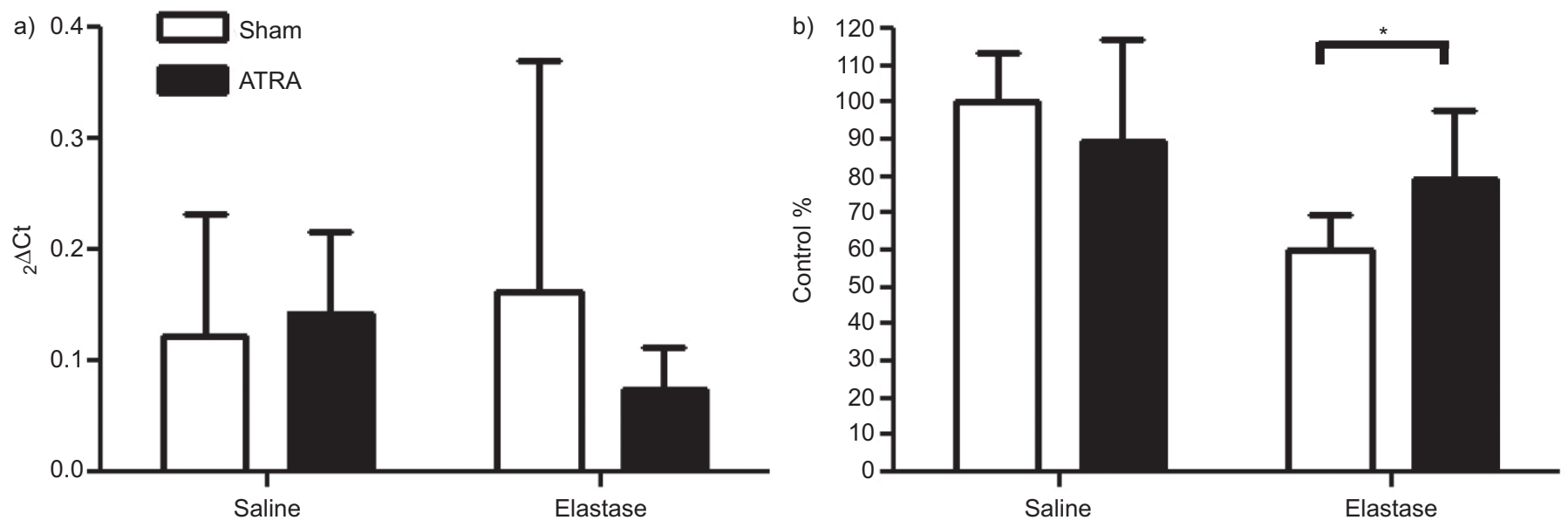

c)

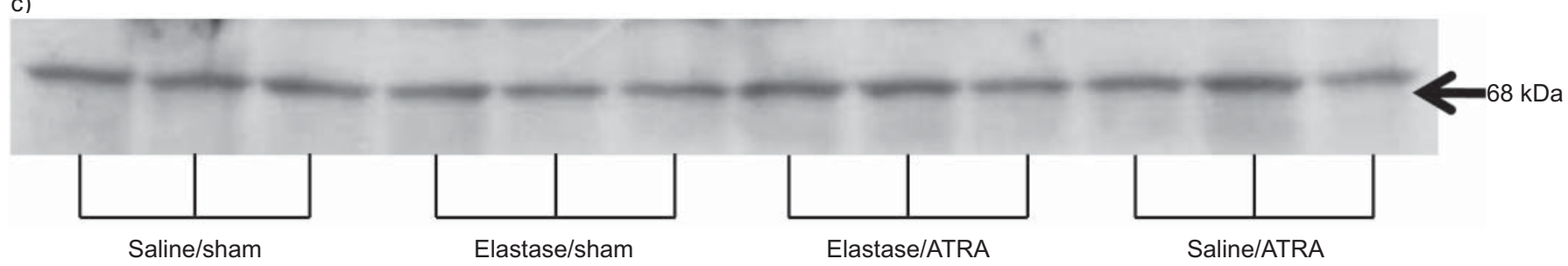

FIGURE 3. Relative mRNA and soluble protein expression for elastin in whole lung tissue homogenate. a) Elastin mRNA expression did not show any significant differences between groups: saline/sham versus saline/ all-trans retinoic acid (ATRA) and elastase/sham versus elastase/ATRA. Expression was determined by means of RTPCR relative to the endogenous reference gene glyceraldehyde-3-phosphate dehydrogenase according to the formula, 2 to the power of delta cycle threshold $\left(2^{\Delta C t}\right)$, where

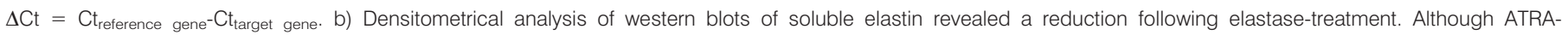
supplementation did not restore control levels, soluble elastin protein was significantly higher in the elastase/ATRA group compared with elastase/sham. Data were analysed by means of the unpaired t-test for significant differences between the groups saline/sham versus saline/ATRA and elastase/sham versus elastase/ATRA, respectively. *: $p \leqslant 0.05$. c) Soluble elastin protein assessed by western blotting in different groups under study.

(fig. 7f) in alveolar macrophages of emphysematous lungs (group ES versus group EA), whereas no effects were seen in WLT homogenate (data not shown). ATRA-therapy had no effects on MMP-7 in emphysematous lungs, either on mRNA expression (fig. $7 \mathrm{~b}$ ) or on protein expression as seen by immunohistochemistry (fig. $7 \mathrm{~g}$ and $\mathrm{h}$ ).

\section{Zymography and reverse zymography: MMP and TIMP activities}

In BAL fluid, enzymatic activity was detectable for MMP-2 (molecular weight $72 \mathrm{kD}$ ) and TIMP-1 (molecular weight $24 \mathrm{kD}$ ) by zymography and reverse zymography, respectively (fig. 8a). Densitometry based quantitative analysis of gels revealed that MMP-2 and TIMP-1 activities were significantly affected by both elastase-treatment and ATRA-therapy (fig. 8b). The activities of MMP-2 and TIMP-1 were increased by 5.1-fold and 1.8fold in emphysematous lungs (groups ES) compared with controls (group SS), respectively. However, reduced activities of MMP-2 (0.35-fold) and TIMP-1 (0.62-fold) were observed in ATRA-treated (group EA) versus vehicle-treated (group ES) emphysematous lungs. In non-emphysematous lungs, enzyme activities did not change with ATRA-supplementation.

\section{DISCUSSION}

Several studies performed to test the hypothesis that ATRA is able to induce regeneration of alveolar gas exchange area and to reverse emphysema reported contradictory results. Some studies in the elastase- or cigarette smoke-induced rat emphysema model reported the reversal of airspace enlargement [6-8] which, however, were mainly based on mean linear intercept measurements, a highly controversially discussed parameter [36]. Focussing on elastase- and cigarette smoke-exposure models of emphysema, only one study using design-based stereology convincingly demonstrated the regeneration of lost alveolar septa after ATRA-therapy [7], whereas others did not find an effect of ATRA on emphysema relevant histological parameters in mice, rats or guinea pigs [9-13]. Limited reversal of functional parameters and of an aerosol-derived measure of airspace size was seen in a papain-induced model of emphysema in dogs [38]. Likewise, clinical studies reported only limited therapeutic effects in humans [15-18]. As species- and strainspecific differences may account for these discrepancies, we used the same rat strain and therapeutic regimen as in the study performed by MASSARO and MASSARO [7]. Despite this, we observed only partial reversal of airspace enlargement and no effect on alveolar gas exchange area. However, a significant increase in alveolar septal tissue mass and arithmetic mean septal thickness and a significant decrease in the alveolar surface area covered by AEC type II was observed, indicative of an irregular remodelling of alveolar septa. At the molecular level, the expression of elastin mRNA and soluble elastin protein, an important extracellular matrix protein, which was recently shown to be an important modifier of both lung development and response to injury in mice [32] was only partially 

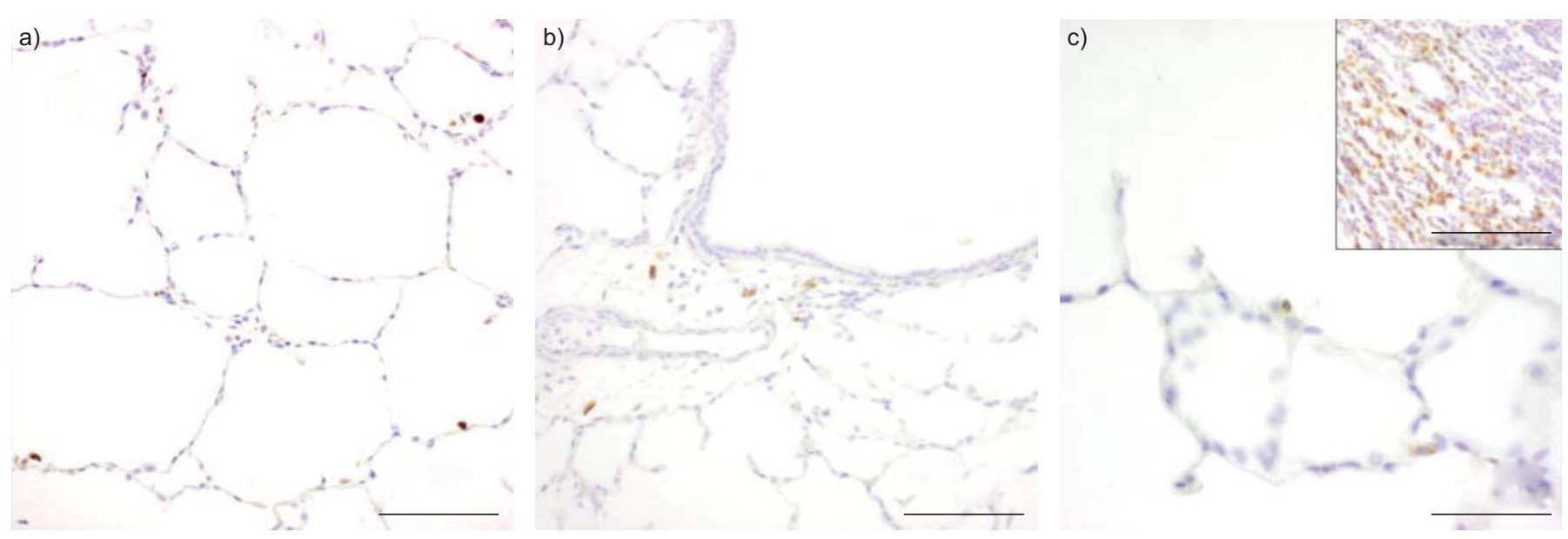

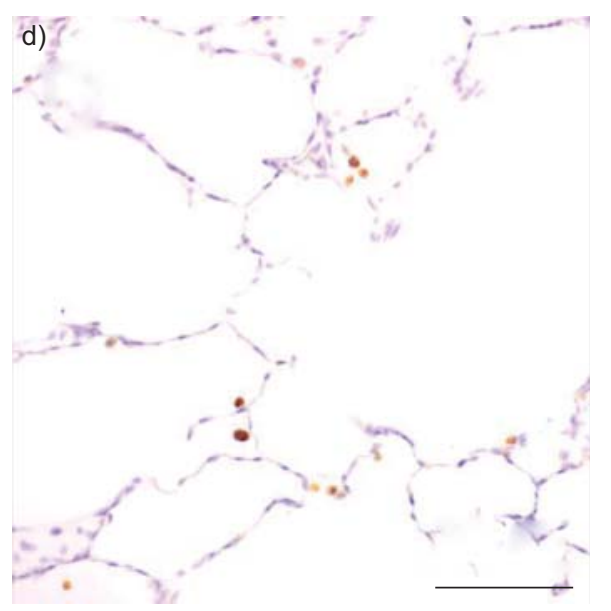

e)

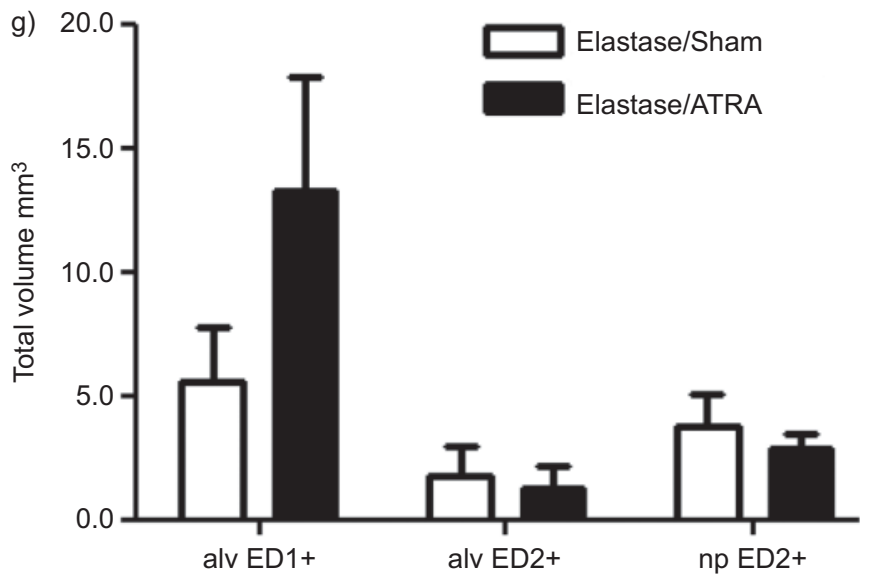

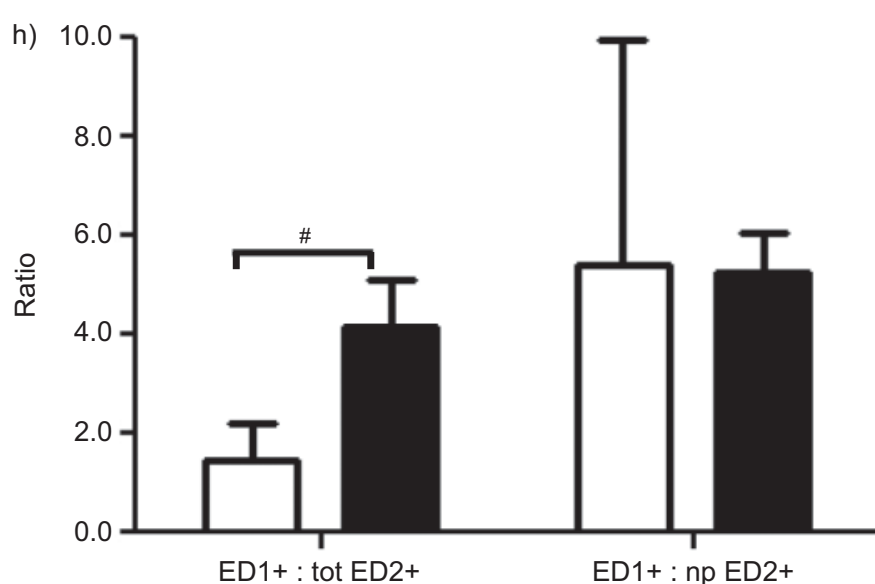

FIGURE 4. Immunohistopathology of inflammatory cells. Dewaxed paraffin sections of lungs from: a, b and c) elastase/sham group; and d, e and f) the elastase/all-trans retinoic acid (ATRA) group. Cells were stained by indirect immunohistochemistry for ED1 ${ }^{+}$alveolar macrophages $(a$ and $d)$, ED2 ${ }^{+}$interstitial macrophages $(b$ and $e)$ and $\alpha / \beta-T$ cell receptor ${ }^{+}$T-lymphocytes (c and f). The insert in c) demonstrates the presence of T-lymphocytes in bronchus-associated lymphatic tissues. ED1 ${ }^{+}$macrophages were the predominant cell type in the alveolar airspace in both groups, whereas T-lymphocytes were rarely seen and most frequently observed with capillaries. Scale bars: $100 \mu \mathrm{m}$ $(a, b$, insert in $\mathrm{c}, \mathrm{d}$ and $\mathrm{e})$ and $50 \mu \mathrm{m}$ ( $\mathrm{c}$ and $\mathrm{f}) . \mathrm{g}$ and $\mathrm{h}$ ) The results of quantitative morphologic analysis of ED1 ${ }^{+}$and ED2 ${ }^{+}$macrophages suggest an increase in ED1 $1^{+}$over $\mathrm{ED} 2^{+}$macrophages in elastase/ATRA versus elastase/sham group. Data were analysed for significant differences using the unpaired t-test. alvED1 ${ }^{+}$: alveolar ED1 ${ }^{+}$ macrophages; alv ED2 ${ }^{+}$: parenchymal ED2 ${ }^{+}$macrophages; $n p \mathrm{ED}^{+}$: non-parenchymal ED2 ${ }^{+}$macrophages; tot ED2 ${ }^{+}$: total ED2 ${ }^{+}$macrophages. ${ }^{\#}: p=0.07$.

ameliorated by ATRA-therapy. Moreover, soluble elastin does not allow any conclusions to be drawn about the deposition of (insoluble) elastin as a component of the extracellular scaffold of alveolar septa. Although the elastase-induced rodent model is highly specific and has clear limitations in the investigation of the pathogenesis of the human disease, it can be used to study potential effects of therapeutics on alveolar septal maintenance and regeneration $[39,40]$. 

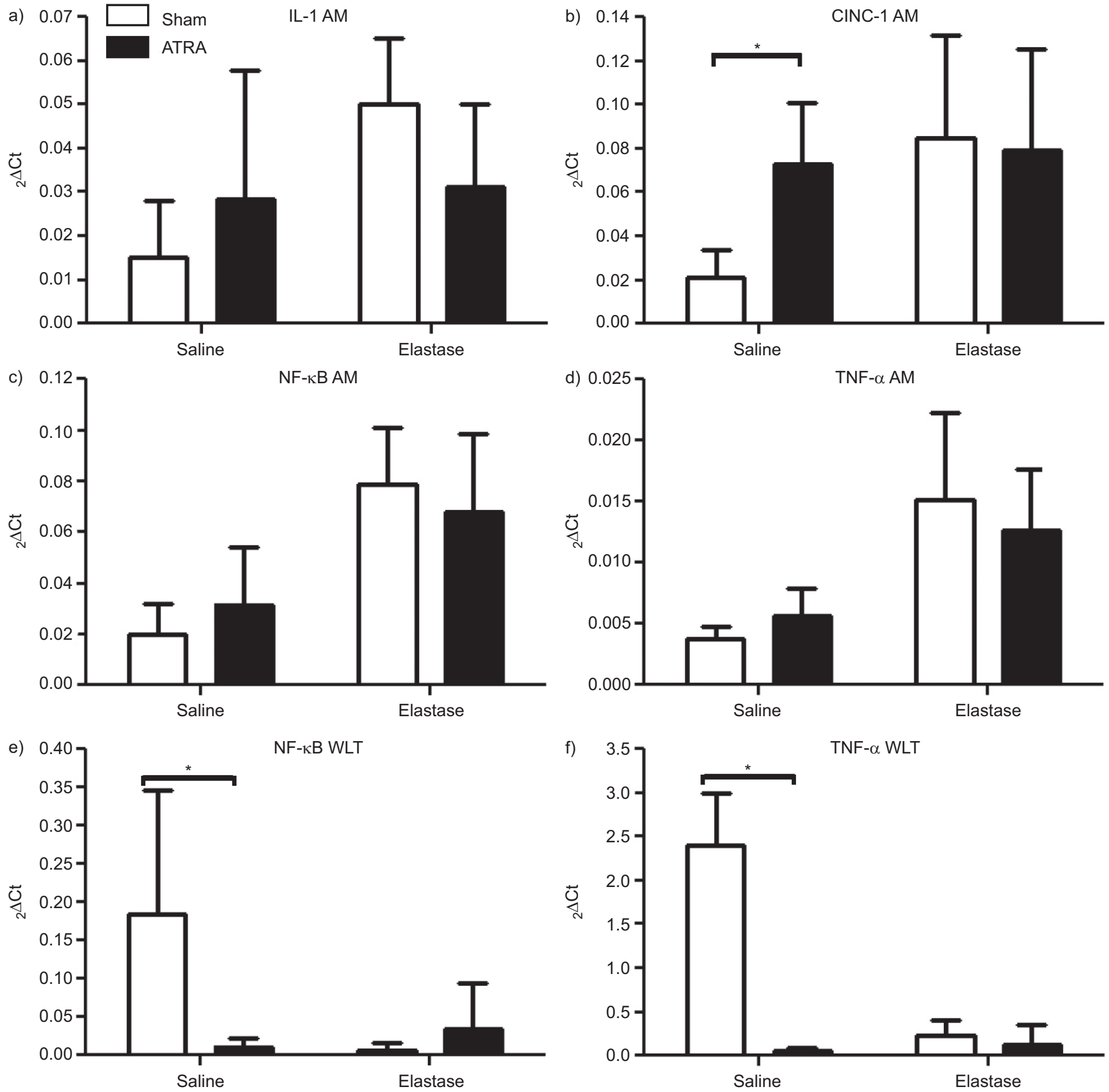

FIGURE 5. Relative mRNA expression of inflammatory mediators in a-d) alveolar macrophages (AM) and e and f) whole lung tissue homogenate (WLT). a) Interleukin (IL)-1, b) cytokine-induced neutrophil chemoattractant (CINC)-1, c) nuclear factor (NF)-KB and d) tumour necrosis factor (TNF)- $\alpha$ were increased in response to elastasetreatment. However, significant effects of all-trans retinoic acid (ATRA) supplementation were only observed with respect to CINC-1 in alveolar macrophages as well as of NF$\kappa B$ and TNF- $\alpha$ in tissues. The mRNA levels of the target genes were determined relative to the endogenous reference gene glyceraldehyde-3-phosphate dehydrogenase according to the formula, 2 to the power of delta cycle threshold $\left(2^{\Delta \mathrm{Ct}}\right)$, where $\Delta \mathrm{Ct}=\mathrm{Ct}_{\text {reference gene- }} \mathrm{Ct}_{\text {target gene. }}$. Data were analysed using the unpaired t-test for significant differences between the groups saline/sham versus saline/ATRA and elastase/sham versus elastase/ATRA, respectively. *: $p \leqslant 0.05$.

Our findings are consistent with data obtained in a canine model of compensatory lung growth following right-sided pneumonectomy. In this model, 4 months of ATRA-supplementation resulted in a significant increase of alveolar septal volume and arithmetic mean thickness, whereas no effect was seen in total alveolar surface area [41]. Quantitative electron microscopic analysis revealed that alveolar septal growth was non-uniform with a selective enhancement of capillary and endothelial growth resulting in a distorted septal architecture accompanied by a decrease in lung diffusion capacity [41]. Analysis of lung function indicated uneven distribution of ventilation consistent with distortion of alveolar geometry and/or altered small 


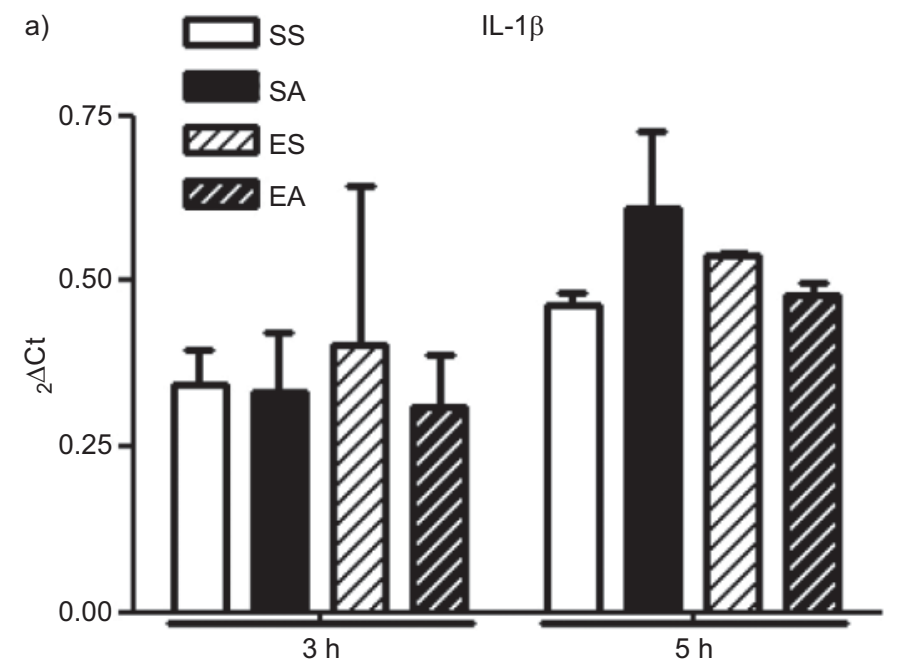

b)

TNF- $\alpha$

c)

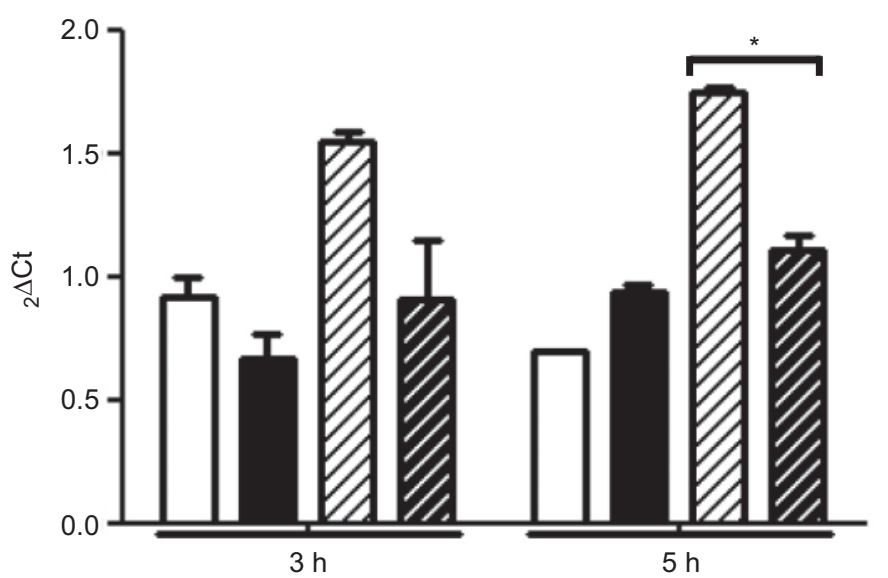

e)

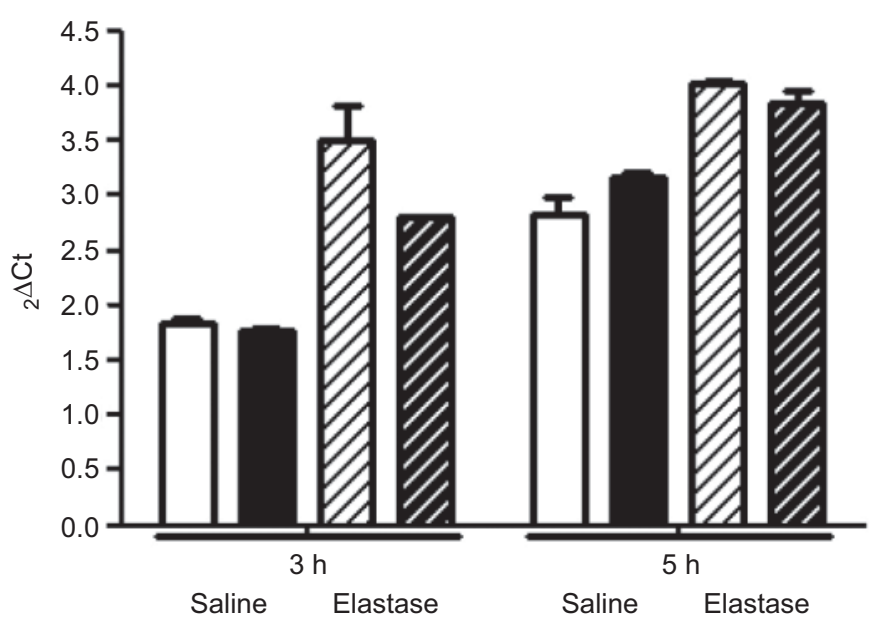

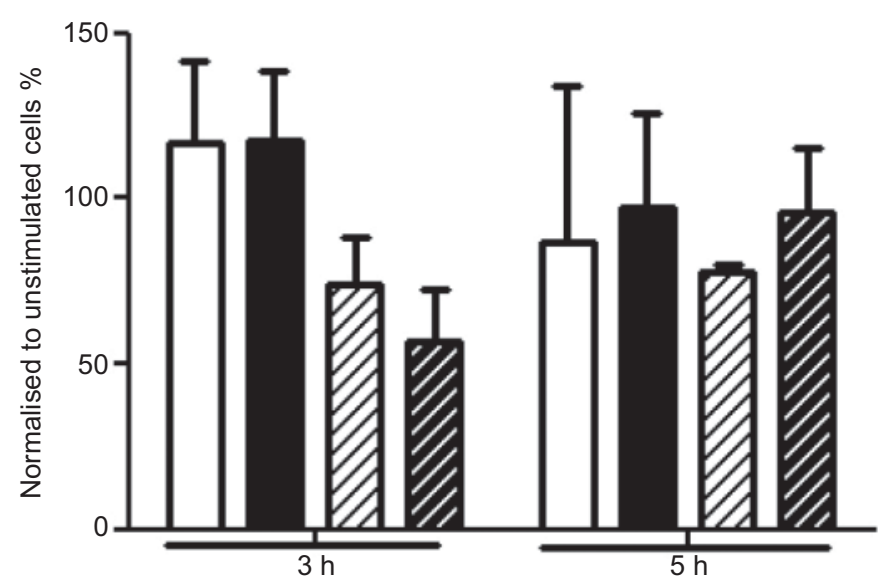

d)

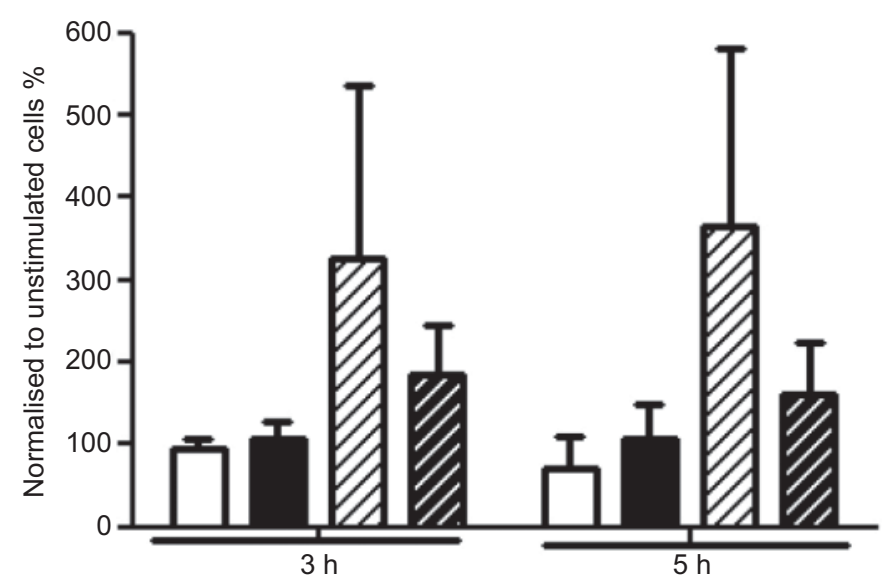

CINC-1

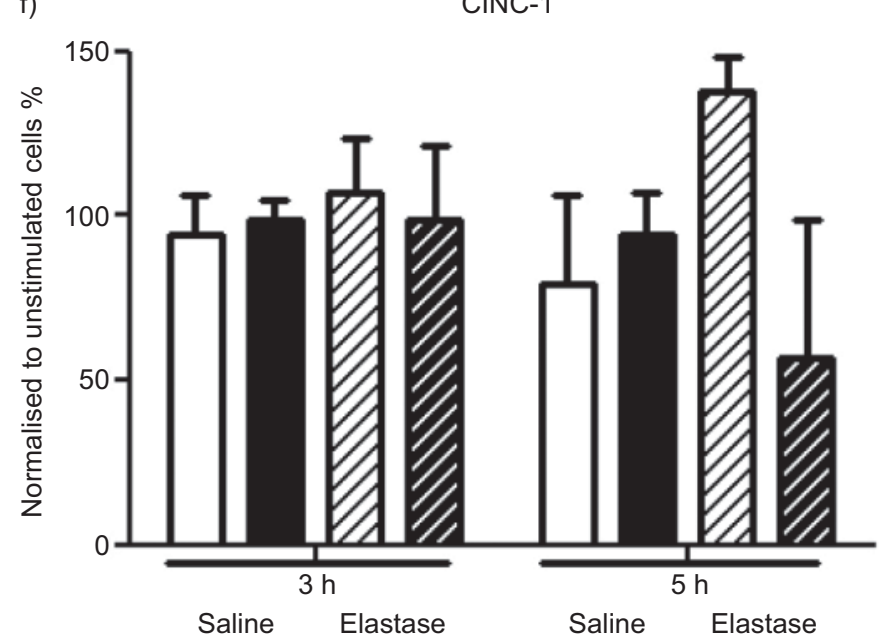

FIGURE 6. $a, c$ and e) Relative mRNA expression and b, $d$ and f) protein release of inflammatory mediators (interleukins (IL), tumour necrosis factor (TNF)- $\alpha$ and cytokine-induced neutrophil chemoattractant (CINC)-1) from rat alveolar epithelial L2 cells. Cells were treated for 3 or $5 \mathrm{~h}$ with $1 \mathrm{mM}$ all-trans retinoic acid (ATRA). 3 or $5 \mathrm{~h}$ later, cells were harvested for RT-PCR and cell supernatants for multiplex analysis. The only significant effect observed was a decrease in mRNA expression of IL-6 after $5 \mathrm{~h}$ in the elastase/ (ATRA) group versus elastase/sham group. Data were analysed using the unpaired t-test for significant differences between the groups saline/sham versus saline/ATRA and elastase/sham versus elastase/ATRA, respectively. ${ }^{*}: p \leqslant 0.05$. 

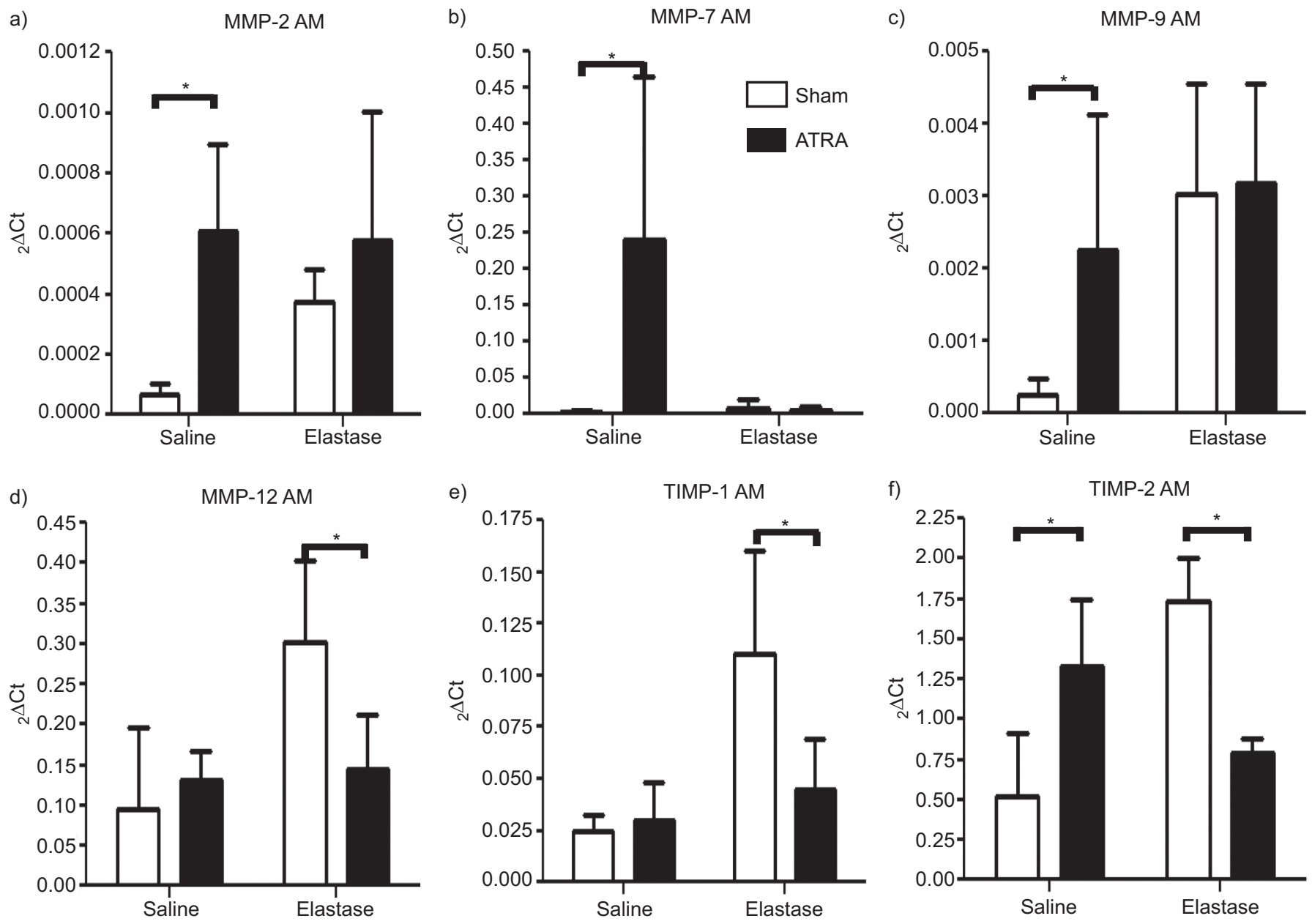

g)

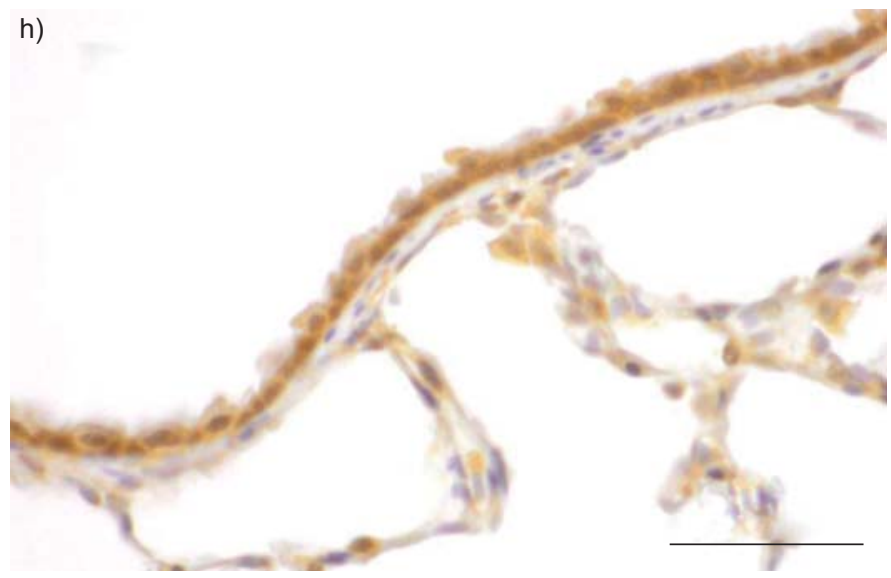

FIGURE 7. Relative mRNA expression of matrix metalloproteinases (MMP) and tissue inhibitor of metalloproteinase (TIMP) in alveolar macrophages (AM). a) MMP-2, b) MMP-7 and c) MMP-9 showed no differences in emphysematous lungs treated with all-trans retinoic acid (ATRA) or olive oil. d) ATRA-supplementation significantly decreased MMP-12 expression in rats treated with elastase. ATRA-supplementation significantly decreased e) TIMP-1 and f) TIMP-2 in rats treated with elastase, whereas TIMP-2 was increased in ATRA-treated healthy lungs. $g$ and $h$ ) Indirect immunohistochemistry revealed no difference in cellular localisation of MMP-7 and intensity in the immune reactivity between $\mathrm{g}$ ) elastase/sham and $\mathrm{h}$ ) elastase/ATRA. The mRNA levels of the target genes were determined relative to glyceraldehyde-3-phosphate dehydrogenase according to

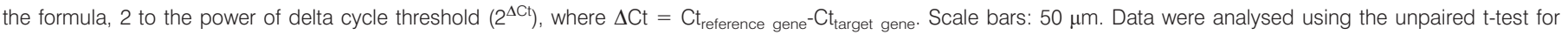
significant differences between the groups saline/sham versus saline/ATRA and elastase/sham versus elastase/ATRA, respectively. ${ }^{*}: p \leqslant 0.05$.

airway function induced by ATRA after right-sided pneumonectomy in the dog [42]. These data are supported by the findings of TEPPER et al. [43] that 2 weeks of supplementation with ATRA had no effect on compliance, forced flows or diffusing capacity of the lung for carbon monoxide in the rat elastase-model of emphysema, although there was a slight, 
a)

Gel 1

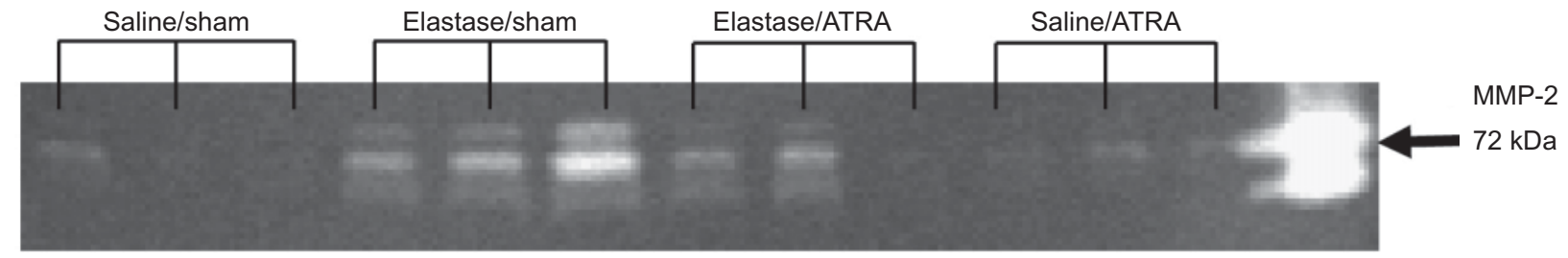

Gel 2

TIMP-1

$24 \mathrm{kDa}$

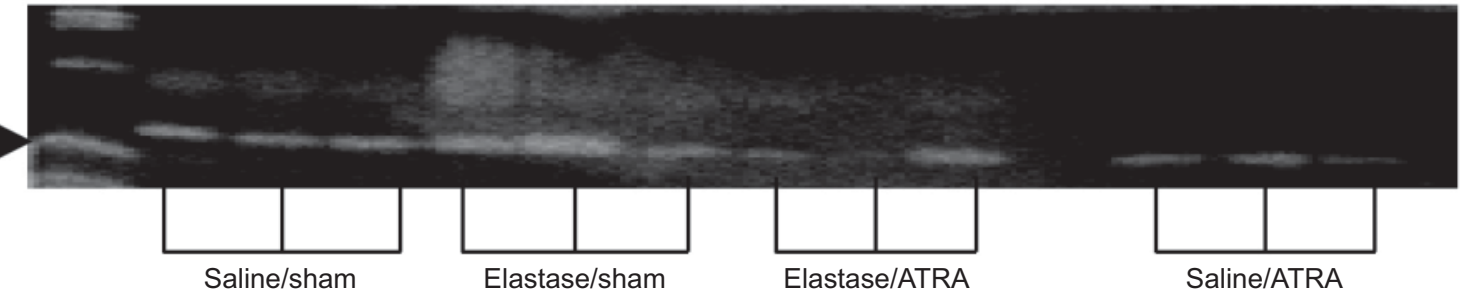

b)

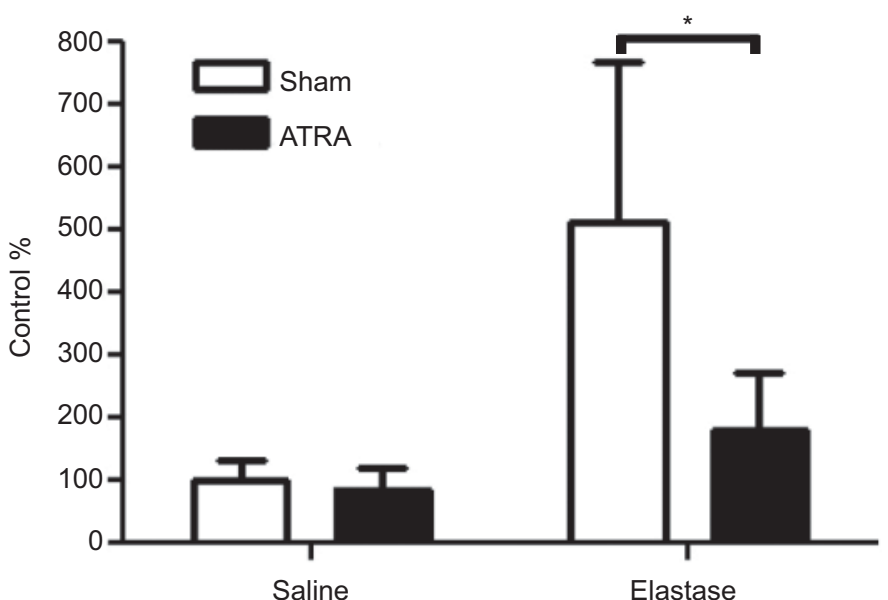

c)

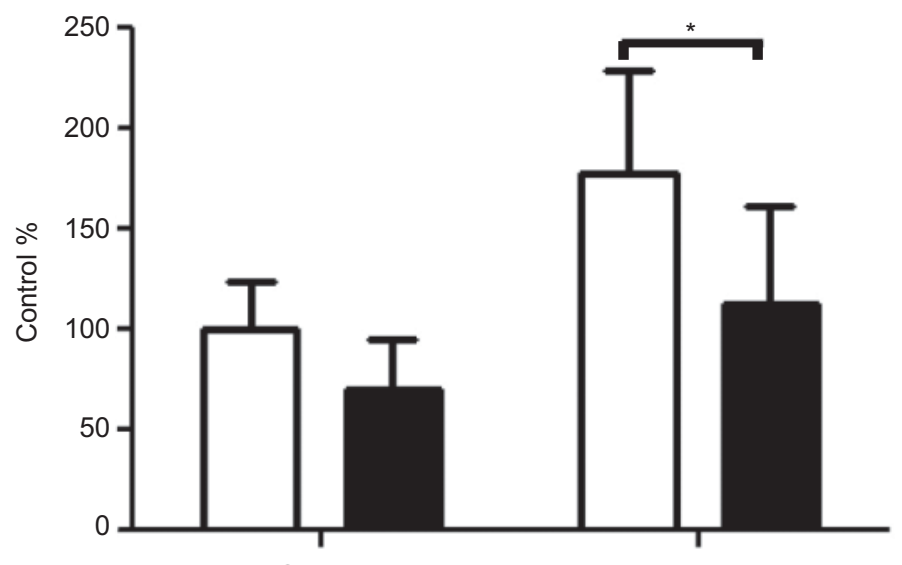

FIGURE 8. Enzymatic activity of matrix metalloproteinases (MMP)-2 and tissue inhibitor of metalloproteinase (TIMP)-1 in bronchoalveolar lavage fluid. a) MMP-2 activity assessed by zymogram gel (gel 1) electrophoresis was highest in elastase-treated rats receiving sham injections (group elastase/sham) and was significantly reduced by alltrans retinoic acid (ATRA)-supplementation as revealed by densitometry (b). Similarly, TIMP-1 activity as assessed by gel 2 reverse zymogram gel electrophoresis was significantly reduced by ATRA in emphysematous lungs (c). Data were analysed using the unpaired t-test for significant differences between the groups saline/sham versus saline/ATRA and elastase/sham versus elastase/ATRA, respectively. *: $p \leqslant 0.05$.

albeit insignificant increase in computed tomography scan lung tissue density. Notably, ATRA-supplementation had no effect on lung function, alveolar structure, or septal ultrastructure after left-sided pneumonectomy in dogs, which suggests that ATRA does not induce compensatory lung growth in the absence of existing cellular growth activities initiated by other primary signals [44]. Hence, the discrepant results of a number of studies may indicate that additional, yet unknown stimuli are necessary to induce and drive regeneration along a pathway leading to a regular architecture of regenerated alveolar septa. Because Marburg, Germany is located at approximately $380 \mathrm{~m}$ above sea level, hypoxia, which was suggested to be a potential factor accounting for the discrepancies observed [19], is unlikely to explain the limited effect of ATRA seen in our study.

To define the reasons why a specific intervention failed is an almost impossible task. Nevertheless, we will discuss some aspects that might be important in this respect: the role of MMPs, TIMPs and alveolar macrophages. Normal tissue growth, repair and remodelling rely on the well balanced interaction of MMPs and their inhibitors, TIMPs, which are produced by inflammatory and by structural cells of the lung $[25,26,31]$. In alveolar macrophages and lung tissues of healthy rats, ATRA impressively induced transcription of MMP-7, which is involved in the control of inflammation [30] and of airway re-epithelialisation [45]. However, ATRA had no significant effect on MMP-7 mRNA expression and immunoreactivity in emphysematous lungs. The failure to induce MMP-7 in emphysematous lungs, which is known to be important for repair, might partly explain the failure of ATRAtherapy to induce regular alveolar regeneration in our study. Given the plethora of MMPs and TIMPs in the lung [26], other proteases such as MMP-14 or other inhibitors such as TIMP-3, which have not been addressed in our study, may additionally contribute to the effects observed. 
ATRA-therapy further enhanced MMP-2 expression in alveolar macrophages of emphysematous lungs, whereas increased TIMP-1 mRNA was significantly decreased. Notably, no changes were seen in whole lung tissue homogenates. The enzymatic activities of MMP-2 and TIMP-1 were significantly reduced in BAL fluid of emphysematous lungs supplemented with ATRA. Similarly, short-term in vitro incubations of human BAL cells with ATRA demonstrated a reduction in both MMP-9 and TIMP-1 at protein and mRNA levels, although at a ratio that was more favourable towards TIMP-1 [46]. Our data suggest that in rats ATRA may result in a net increase in the enzyme activity of MMP-2 over TIMP-1 in BAL fluid compared with control lungs, thus impairing the potential beneficial effects.

MMP-2 levels were correlated with the severity of airflow obstruction and disease progression in chronic obstructive pulmonary disease (COPD) patients $[29,47,48]$. Several in vitro studies suggest that ATRA affects MMP and TIMP expression. Incubation with ATRA decreased the production and activity of MMP-2 and MMP-9, and increased TIMP-1 and TIMP-2 in capillary endothelial cells [49]. ATRA resulted in decreased MMP-9 and increased TIMP-1 in alveolar macrophages from COPD patients [46]. Likewise, ATRA reduced production and activity of MMP-9 in alveolar macrophages obtained from smokers with COPD compared with untreated cells from the same subjects, whereas no changes were seen in alveolar macrophages of nonsmokers [16]. However, as incubation of regenerating AEC with TIMPs resulted in abnormal epithelial differentiation [50] and an inhibition of MMP-7 activity [51], a shift to a preponderance of TIMPs may give rise to an unintended negative effect on epithelial repair and promote airway fibrosis [51].

MMP expression was previously shown to be regulated at the transcriptional level by TNF- $\alpha$ via NF- $\mathrm{BB}$ signalling in several cell types including AEC $[52,53]$. In this context, a further interesting finding of our study was that alveolar macrophages exhibited a persistently high expression of pro-inflammatory mediators that might counteract the potentially beneficial effects of ATRA. Instillation of elastase induces an early inflammatory response dominated by neutrophils and alveolar macrophages in rats and mice, which is almost completely resolved after 7-20 days [54-56]. Likewise, inflammation was morphologically no longer seen in rat lungs 38 days after elastase-instillation in our study. Alveolar macrophages were the predominant inflammatory cell type present in distal lungs. However, inflammatory mediators such as TNF- $\alpha$, IL-1 and CINC-1 as well as the pro-inflammatory transcription factor NF- $\kappa B$ were still significantly increased compared with the controls, suggesting a persistent pro-inflammatory state of alveolar macrophages even $>5$ weeks after the initial injury. In line with this, we observed an increase in $\mathrm{ED}^{+}$alveolar macrophages in emphysematous rats treated with ATRA, whereas no effect was seen in macrophages binding mAb ED2, which recognises CD163, a regulated haemoglobin scavenger receptor involved in the down-modulation of inflammatory responses [57]. Likewise, ATRA did not affect the expression levels of cytokines in WLT of emphysematous lungs and had only limited effects in AEC in our in vitro experiments.

Taken together, the current study indicates that in the rat elastase-model of emphysema ATRA therapy may lead to an irregular architecture of alveolar septa. We speculate that this might relate to the persistently high expression of pro-inflammatory cytokines of alveolar macrophages seen in emphysematous lungs, the failure to induce MMP-7 and an altered MMP/TIMP balance. We cannot present a definite conclusion about the potential cause-and-effect relationships, but our findings suggest that ATRA therapy may carry a risk of unwanted side-effects on the alveolar septal architecture.

\section{SUPPORT STATEMENT}

The study was supported by a grant from Deutsche Forschungsgemeinschaft (FE287/8-1; EXC 306, Cluster of Excellence "Inflammation at Interfaces") and by the LOEWE-Centre Universities of Giessen and Marburg Lung Centre (UGMLC).

\section{STATEMENT OF INTEREST}

Statements of interest for C. Seifart, A. Plagens and C. Vogelmeier can be found at www.erj.ersjournals.com/site/misc/statements.xhtml

\section{ACKNOWLEDGEMENTS}

We would like to thank T. Rausch and L. Greif (Clinical Research Group Chronic Airway Diseases, Philipps University, Marburg, Germany), G. Fuchs-Moll (Justus-Liebig-University Giessen, Giessen, Germany) and F. Ganzert and D. Karp (Leibniz Center for Medicine and Biosciences, Borstel, Germany) for their excellent technical assistance. We thank B. Wenske (Hannover Medical School, Hannover, Germany) for her help in the establishment of the elastase model of emphysema.

\section{REFERENCES}

1 American Thoracic Society. Standards for the diagnosis and care of patients with chronic obstructive pulmonary disease. Am J Respir Crit Care Med 1995; 152: S77-S121.

2 Massaro GD, Massaro D. Postnatal treatment with retinoic acid increases the number of pulmonary alveoli in rats. Am J Physiol 1996; 270: L305-L310.

3 Hind M, Maden M. Retinoic acid induces alveolar regeneration in the adult mouse lung. Eur Respir J 2004; 23: 20-27.

4 Garber SJ, Zhang H, Foley JP, et al. Hormonal regulation of alveolarization: structure-function correlation. Respir Res 2006; 7: 47.

5 Stinchcombe SV, Maden M. Retinoic acid induced alveolar regeneration: critical differences in strain sensitivity. Am J Respir Cell Mol Biol 2008; 38: 185-191.

6 Belloni PN, Garvin L, Mao CP, et al. Effects of all-trans-retinoic acid in promoting alveolar repair. Chest 2000; 117: 235S-241S.

7 Massaro GD, Massaro D. Retinoic acid treatment abrogates elastase-induced pulmonary emphysema in rats. Nat Med 1997; 3: 675-677.

8 Ofulue AF, Xiang AF, Yang $\mathrm{Y}$, et al. Retinoids reverse cigarette smoke induced emphysema in rats. Am J Respir Crit Care Med 2002; 165: A137.

9 Fujita M, Ye Q, Ouchi $\mathrm{H}$, et al. Retinoic acid fails to reverse emphysema in adult mouse models. Thorax 2004; 59: 224-230.

10 Lucey EC, Goldstein RH, Breuer R, et al. Retinoic acid does not affect alveolar septation in adult FVB mice with elastase-induced emphysema. Respiration 2003; 70: 200-205.

11 March TH, Cossey PY, Esparza DC, et al. Inhalation administration of all-trans-retinoic acid for treatment of elastase-induced pulmonary emphysema in Fischer 344 rats. Exp Lung Res 2004; 30: 383-404.

12 March TH, Bowen LE, Finch GL, et al. Effects of strain and treatment with inhaled all-trans-retinoic acid on cigarette smokeinduced pulmonary emphysema in mice. COPD 2005; 2: 289-302.

13 Meshi B, Vitalis TZ, Ionescu D, et al. Emphysematous lung destruction by cigarette smoke. The effects of latent adenoviral 
infection on the lung inflammatory response. Am J Respir Cell Mol Biol 2002; 26: 52-57.

14 Yoshimatsu A, Nan-ya K, Miki I. Effect of nartograstim, a recombinant human granulocyte colony-stimulating factor on elastase-induced emphysema in rats. Arzneimittelforschung 2009; 59: 248-253.

15 Frankenberger M, Heimbeck I, Moller W, et al. Inhaled all-trans retinoic acid in an individual with severe emphysema. Eur Respir J 2009; 34: 1487-1489.

16 Mao JT, Tashkin DP, Belloni PN, et al. All-trans retinoic acid modulates the balance of matrix metalloproteinase- 9 and tissue inhibitor of metalloproteinase-1 in patients with emphysema. Chest 2003; 124: 1724-1732.

17 Mao JT, Goldin JG, Dermand J, et al. A pilot study of all-transretinoic acid for the treatment of human emphysema. Am J Respir Crit Care Med 2002; 165: 718-723.

18 Roth MD, Connett JE, D'Armiento JM, et al. Feasibility of retinoids for the treatment of emphysema study. Chest 2006; 130: 1334-1345.

19 Massaro D, Massaro GD. Toward therapeutic pulmonary alveolar regeneration in humans. Proc Am Thorac Soc 2006; 3: 709-712.

20 Liebeskind A, Srinivasan S, Kaetzel D, et al. Retinoic acid stimulates immature lung fibroblast growth via a PDGF-mediated autocrine mechanism. Am J Physiol Lung Cell Mol Physiol 2000; 279: L81-L90.

21 Maden M. Retinoids have differing efficacies on alveolar regeneration in a dexamethasone-treated mouse. Am J Respir Cell Mol Biol 2006; 35: 260-267.

22 Zhao L, Leung JK, Yamamoto H, et al. Identification of p311 as a potential gene regulating alveolar generation. Am J Respir Cell Mol Biol 2006; 35: 48-54.

23 Clerch LB, Baras AS, Massaro GD, et al. DNA microarray analysis of neonatal mouse lung connects regulation of KDR with dexamethasone-induced inhibition of alveolar formation. Am J Physiol Lung Cell Mol Physiol 2004; 286: L411-L419.

24 Burri PH. Structural aspects of postnatal lung development alveolar formation and growth. Biol Neonate 2006; 89: 313-322.

25 Greenlee KJ, Werb Z, Kheradmand F. Matrix metalloproteinases in lung: multiple, multifarious, and multifaceted. Physiol Rev 2007; 87: 69-98.

26 Ryu J, Vicencio AG, Yeager ME, et al. Differential expression of matrix metalloproteinases and their inhibitors in human and mouse lung development. Thromb Haemost 2005; 94: 175-183.

27 Belvisi MG, Bottomley KM. The role of matrix metalloproteinases (MMPs) in the pathophysiology of chronic obstructive pulmonary disease (COPD): a therapeutic role for inhibitors of MMPs? Inflamm Res 2003; 52: 95-100.

28 Elkington PT, Friedland JS. Matrix metalloproteinases in destructive pulmonary pathology. Thorax 2006; 61: 259-266.

29 Baraldo S, Bazzan E, Zanin ME, et al. Matrix metalloproteinase-2 protein in lung periphery is related to COPD progression. Chest 2007; 132: 1733-1740.

30 Parks WC. Matrix metalloproteinases in lung repair. Eur Respir J 2003; 22: 36S-38S.

31 Parks WC, Shapiro SD. Matrix metalloproteinases in lung biology. Respir Res 2001; 2: 10-19.

32 Shifren A, Durmowicz AG, Knutsen RH, et al. Elastin protein levels are a vital modifier affecting normal lung development and susceptibility to emphysema. Am J Physiol Lung Cell Mol Physiol 2007; 292: L778-L787.

33 Fehrenbach H, Zimmermann G, Starke E, et al. Nitrogen dioxide induces apoptosis and proliferation but not emphysema in rat lungs. Thorax 2007; 62: 438-446.

34 Hirschburger M, Zakrzewicz A, Kummer W, et al. Nicotine attenuates macrophage infiltration in rat lung allografts. J Heart Lung Transplant 2009; 28: 493-500.

35 Fehrenbach H, Kasper M, Tschernig T, et al. Keratinocyte growth factor-induced hyperplasia of rat alveolar type II cells in vivo is resolved by differentiation into type I cells and by apoptosis. Eur Respir J 1999; 14: 534-544.

36 Hsia CC, Hyde DM, Ochs M, et al. An official research policy statement of the American Thoracic Society/European Respiratory Society: standards for quantitative assessment of lung structure. Am J Respir Crit Care Med 2010; 181: 394-418.

37 Muyal JP, Muyal V, Kaistha BP, et al. Systematic comparison of RNA extraction techniques from frozen and fresh lung tissues: checkpoint towards gene expression studies. Diagn Pathol 2009; 4: 9.

38 Rosenthal FS. Aerosol probes of emphysema progression in dogs treated with all trans retinoic acid - an exploratory study. J Aerosol Med 2007; 20: 83-96.

39 Schmiedl A, Lempa T, Hoymann HG, et al. Elastase-induced lung emphysema in rats is not reduced by hematopoietic growth factors when applied preventionally. Virchows Arch 2008; 452: 675-688.

40 Yildirim AO, Muyal V, John G, et al. Palifermin induces alveolar maintenance programs in emphysematous mice. Am J Respir Crit Care Med 2010; 181: 705-717.

41 Yan X, Bellotto DJ, Foster DJ, et al. Retinoic acid induces nonuniform alveolar septal growth after right pneumonectomy. J Appl Physiol 2004; 96: 1080-1089.

42 Dane DM, Yan X, Tamhane RM, et al. Retinoic acid-induced alveolar cellular growth does not improve function after right pneumonectomy. J Appl Physiol 2004; 96: 1090-1096.

43 Tepper J, Pfeiffer J, Aldrich M, et al. Can retinoic acid ameliorate the physiologic and morphologic effects of elastase instillation in the rat? Chest 2000; 117: 242S-244S.

44 Yan X, Bellotto DJ, Dane DM, et al. Lack of response to all-trans retinoic acid supplementation in adult dogs following left pneumonectomy. J Appl Physiol 2005; 99: 1681-1688.

45 Dunsmore SE, Saarialho-Kere UK, Roby JD, et al. Matrilysin expression and function in airway epithelium. J Clin Invest 1998; 102: 1321-1331.

46 Frankenberger M, Hauck RW, Frankenberger B, et al. All transretinoic acid selectively down-regulates matrix metalloproteinase- 9 (MMP-9) and up-regulates tissue inhibitor of metalloproteinase-1 (TIMP-1) in human bronchoalveolar lavage cells. Mol Med 2001; 7: 263-270.

47 Cataldo D, Munaut C, Noel A, et al. MMP-2- and MMP-9-linked gelatinolytic activity in the sputum from patients with asthma and chronic obstructive pulmonary disease. Int Arch Allergy Immunol 2000; 123: 259-267.

48 Chen Y, Chen P, Hanaoka M, et al. Enhanced levels of prostaglandin E2 and matrix metalloproteinase-2 correlate with the severity of airflow limitation in stable COPD. Respirology 2008; 13 : 1014-1021.

49 Braunhut SJ, Moses MA. Retinoids modulate endothelial cell production of matrix-degrading proteases and tissue inhibitors of metalloproteinases (TIMP). J Biol Chem 1994; 269: 13472-13479.

50 Coraux C, Martinella-Catusse C, Nawrocki-Raby B, et al. Differential expression of matrix metalloproteinases and interleukin-8 during regeneration of human airway epithelium in vivo. J Pathol 2005; 206: 160-169.

51 Chen P, McGuire JK, Hackman RC, et al. Tissue inhibitor of metalloproteinase-1 moderates airway re-epithelialization by regulating matrilysin activity. Am J Pathol 2008; 172: 1256-1270.

52 Rahman I. Regulation of nuclear factor- $\mathrm{\kappa} B$, activator protein- 1 , and glutathione levels by tumor necrosis factor- $\alpha$ and dexamethasone in alveolar epithelial cells. Biochem Pharmacol 2000; 60: 1041-1049.

53 Grivennikov SI, Kuprash DV, Liu ZG, et al. Intracellular signals and events activated by cytokines of the tumor necrosis factor superfamily: from simple paradigms to complex mechanisms. Int Rev Cytol 2006; 252: 129-161.

54 Birrell MA, Wong S, Hele DJ, et al. Steroid-resistant inflammation in a rat model of chronic obstructive pulmonary disease is associated with a lack of nuclear factor-кB pathway activation. Am J Respir Crit Care Med 2005; 172: 74-84. 
55 Ishii $Y$, Itoh K, Morishima Y, et al. Transcription factor Nrf2 plays a pivotal role in protection against elastase-induced pulmonary inflammation and emphysema. J Immunol 2005; 175: 6968-6975.

56 Plantier L, Marchand-Adam S, Antico VG, et al. Keratinocyte growth factor protects against elastase-induced pulmonary emphysema in mice. Am J Physiol Lung Cell Mol Physiol 2007; 293: L1230-L1239.

57 Moestrup SK, Moller HJ. CD163: a regulated hemoglobin scavenger receptor with a role in the anti-inflammatory response. Ann Med 2004; 36: 347-354. 